The present document is the pre-print version of the article. The final printed version can be found at: https://www.sciencedirect.com/science/article/pii/S1755581718300464?via\%3Dihub,

https://doi.org/10.1016/j.cirpj.2018.08.001

\title{
PSS cost engineering: a model-based approach for concept design
}

Manufacturing companies are increasingly moving toward delivering combinations of products and services to provide higher value to their customers. The development of such Product Service Systems (PSS) escalates in complexity when several products developed by different suppliers need to be integrated into a unique system. For first tier suppliers, it is a great challenge to model and simulate the impact of changing design variables at the micro-level on both hardware properties and governing behaviours of services over the entire lifecycle of the PSS. The paper describes a model-based approach developed to estimate the life cycle cost of a PSS hardware already at a concept design stage. The proposed approach computes the relative cost efficiency of a set of design variants using as input the data generated by the simulations run in the Computer Aided Engineering (CAE) environment. The approach allows the exploration of the design space of a PSS given by the variation of the geometry of a Computer Aided Design (CAD) model, building on the computation of customised cost modules selected by a generic list of PSS cost dimensions. For each evaluated design case, the model produces as output a unique monetary figure of the cost expected to incur by owning or using the asset throughout the lifetime. The work has been conducted in collaboration with a tier-one aerospace component manufacturer, and the application of the model is exemplified through a case study related to the development of a turbine rear structure (TRS) for commercial jet engines. The approach is most suitable for the development of complex systems in which new products and components are integrated into a shared product platform. The results are discussed in relation to the current literature on PSS cost engineering, highlighting challenges to be addressed to increase cost estimation accuracy and increase uncertainty identification and awareness.

Keywords: Product-Service Systems; cost engineering; concept design; product development; Life cycle cost, aerospace. 


\section{Introduction}

It is largely acknowledged that manufacturing companies are increasingly expanding their business strategy by integrating services in their product offer. This phenomenon is commonly described in literature with the term 'servitization' (Goedkoop et al., 1999), and is further cascaded down to several business initiatives such as Product-Service Systems (PSS) (Goedkoop et al., 1999), Total Offers (Alonso-Rasgado et al., 2004), Industrial Product Service Systems (Meier et al., 2010) or Functional Products (Löfstrand et al. 2011). Despite different names and definitions, they emphasize the new role played by manufacturers in the value chain. By moving away from typical 'onesale' models, they become providers of total solutions that focus on the delivery of 'desired outcomes' by combining products and services (Lightfoot et al., 2013). This servitization trend can be observed in a variety of industrial sectors, from electronics to IT, from process industries to transportation and aerospace (see for instance Baines et al., 2009; Kumar and Markeset, 2011; Ahamed et al., 2013; Visintin, 2014, Wallin, 2013; Wallin et al., 2015). In turn, this trend affects design and development activities: newly introduced requirements on service provision shuffle design priorities and emphasize the need for new metrics to trade-off hardware vs. service elements (Morelli, 2006; Monceaux et al., 2014). The engineering teams dealing with the development of the hardware find themselves in need to trade off 'traditional' engineering dimensions (e.g. geometry, weight) with other value-creating factors (e.g., serviceability, upgradeability) related to the later stages of the product life cycle.

Identifying the right trade-off since the concept design stage is a major challenge today for those manufacturing organizations implementing servitised business models. This challenge is emphasized when designing hardware and components for complex engineering systems, an activity commonly referred to in System Engineering literature as "Sub-System design" (Blanchard et al., 1990). Here, the complexity of a new technical solution, and its interdependency with other systems, often means for the engineering tem to search for the optimum within a strict, pre-defined design space, iteratively building on pre-existing product platforms (Isaksson et al. 2013; Levandowski et al. 2014). Hence, sub-systems are typically selected based on their technical feasibility and performance, rather than on a systematic exploration of the life cycle value and costs associated with new solutions. Nowadays, design support tools are capable to discriminate performances between hundreds of design variations. However, life cycle cost models are often not available at the same level of detail. Even though they provide a high-level assessment of life cycle costs, they are not able to calculate positive or negative cost deltas among different configurations of the same platform. In sub-system design, established methods to estimate the cost of a future PSS solutions - such as Total Cost of Ownership (Ellram, 1993), Through Life Costing (Newnes et al., 2011) and Life Cycle Costing (LLC) (Woodward, 1997) - are of limited benefit, due to the high volatility of the concept design information and the high number of design variants that shall be assessed concurrently. 
The research presented in this paper addresses the need to explore the life cycle cost of sub-system design variations of a hardware to be integrated into a system provided as PSS. The research investigates the question:

"How can a model-based approach support the estimation of the life cycle cost of a PSS hardware already at a concept design stage?"

The paper proposes a model-based approach for life cycle cost estimations that is based on the results of concept design simulations run to explore the feasible design space in a Computer Aided Engineering (CAE) environment. The approach is exemplified in a case conducted in collaboration with a tier-one aero-engine sub-system manufacturer that deals with the development of a turbine rear structure (TRS) for commercial jet engines. Within the case study, the goal was to compute the relative cost efficiency among a set of TRS platform variants (also called Design Cases). A main feature of the approach is the ability to run cost estimation based on an open range of possible design cases, rather than on a predefined set of solutions. The approach is built by modular computational blocks, which enable design engineers to obtain relative cost comparisons between the most relevant variables for a specific context.

The paper first presents the research approach based on the Design Research Methodology and enabled by Participatory Action Research. Section 3 reviews the main approaches for PSS cost engineering available in the literature. Section 4 presents the findings from the descriptive study, highlighting the expected capabilities of the approach as emerged from the empirical study. Section 5 describes the overall logic of the model-based PSS cost engineering approach. Section 6 illustrates its application for the development of the TRS. Section 7 discusses the approach in the light of its contribution to PSS design. It presents the results of verification activities conducted with the partner company and elaborates on areas of future improvement. Section 8 draws the final conclusions.

\section{Research approach}

A participatory action research approach (PAR) (Whyte et al. 1989) has guided the development of the model-based approach and its verification within the case study. PAR involves the direct participation or researchers and practitioners in research design and development, with the aim of solving practical problems that also have important theoretical implications (Whyte et al., 1989). Similarly to action research, PAR involves Look-Think-Act cycles in which the researcher tests a theory with practitioners in real situations, gains feedback from this experience, and modifies the theory as a result of this feedback (Avison et al., 1999).

PAR is often criticized for lacking academic standardization and for limiting the independence of researchers (McNiff, 2014). To mitigate the issue with lack of rigor and technical validity in research, the application of PAR is steered by the Design Research Methodology (DRM) framework proposed by Blessing and Chakrabarti (2009). The latter focuses on the formulation and validation of models and theories of 
design, together with the development and the validation of support founded on such models and theories, with the final intent to improve the design practice (Blessing and Chakrabarti, 2009). DRM consists of four non-linear stages. In the Research Clarification stage, problems are investigated and literature explored. In the Descriptive Study I stage, researchers shall define an AS-IS model of the specific design situation being investigated. In the Prescriptive Study stage, the desired design support is ideated and developed. In the final Descriptive Study II stage, the effectiveness of the actual support shall be evaluated.

PAR and DRM cope with different objectives and fulfill different needs. Yet, they are found to mutually nurture each other for the benefit of researchers, mainly in the way DRM stresses the validation of a design support in term of generic statements of partial implementation, while PAR draws conclusions about a specific support in a specific situation (Blessing and Chakrabarti, 2009).

In line with PAR guidelines (Whyte et al., 1989), the research process kicked-off with the identification of the problems faced in the company environment. While collecting data from the field, literature was analyzed to clarify the research challenges and generalize the problem definition at a cross-disciplinary level, to overcome the problem of focusing on a single discipline behavior (Whyte et al. 1989). A range of qualitative methods was used to collect empirical data, paying attention to data triangulation so to mitigate the limitations of each single data collection method (Speziale et al., 2011). The main mode of data collection in the Descriptive Study I stage were semi-structured interviews, which served the purpose of collecting specific information from individuals with different roles in the company. When possible, interviews were recorded and transcribed, to be further validated by the respondents. When the audio recording was not allowed, notes were taken during the interviews. An extended report was produced directly after each interview and forwarded to each respondent for feedback. Interviews were complemented by focus groups to: "capitalize on communication between the research participants in order to generate data" (Kitzinger, 1995 pp. 299). Participants observation took place at the partner company facilities during projects meetings (and documented through field notes). They made possible for the researchers to capture the context and the setting in which the problem was discussed, and to record behaviors and reactions. Internal company documents and publicly available information describing the existing engineering processes were also analyzed for triangulation purpose.

The prescriptive development of the model-based approach (corresponding to what is generically defined as "support" according to the DRM) started with the definition of the requirements of the "intended support" (i.e. the ideal solution for the design problem) and was followed by the realization of the actual support (i.e. the implementation of the "intended support" in a specific case) taking as a reference case the design of an aircraft engine component (i.e. the TRS). Such process featured a series of Look-Think-Act loops (Avison et al., 1999) between researchers and practitioners to incrementally improve the proposed solution by constant verification and validation activities (Whyte et al. 1989).

The last step of the research consisted in the verification and evaluation of the actual support, following the guidelines of the Descriptive Study II of the DRM (Blessing and 
Chakrabarti, 2009). Here the activity focused on the 'Support Evaluation' and on the 'Application Evaluation'. Support Evaluation aimed at ensuring that the 'actual support' was developed to such an extent that it could be evaluated. and implied the physical test of the computational capabilities on the approach based on the TRS case, so to ensure that all the desired functions of the approach were available. Application Evaluation aimed at verifying the applicability and usability of the support in relation to the desired performances and users. This implied the involvement of industrial practitioners in testing and evaluating the support providing feedback for continuous improvement. In line with the Look-Think-Act loops, both evaluation activities were not linear, rather they were part of the continuous improvement activities during the development of the support.

Validation activities did not encompass 'Success Evaluation', i.e. the evaluation and measurement of the impact of the actual support on the company performances. The length and complexity of new aerospace development projects, in fact, makes it difficult to measure and quantify the impact of a specific support method in a relevant timeframe. Figure 1 shows how PAR and DRM were coupled in the research, and how the work was iteratively conducted in the case study.

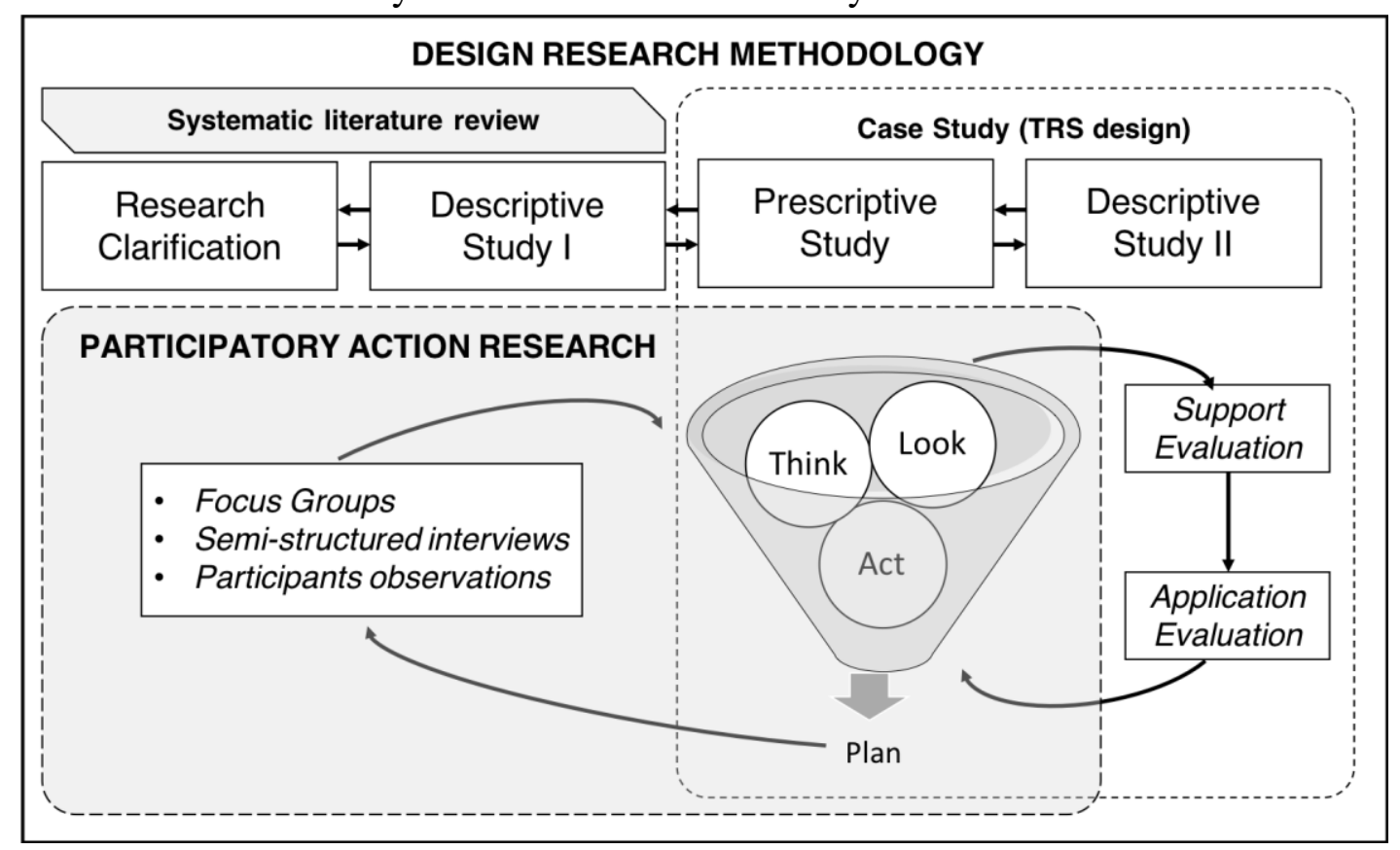

Figure 1. Coupling Participatory Action Research (PAR) and Design Research Methodology (DRM)

\subsection{Systematic literature review approach}

A systematic literature review was conducted using Scopus - one of the largest abstract and citation database of peer-reviewed literature - to gather existing contributions in the field of PSS cost engineering. Research contributions published in Procedia CIRP from the Industrial Product Service Systems (CIRP IPSS) and Life Cycle Engineering (CIRP LCE) conferences were initially reviewed to identify synonyms for both 'Product Service Systems' and 'cost engineering' to be included in the search string. This list of keywords was further expanded following the recommendations received during the review process, to eventually obtain the following string: 
TITLE-ABS-KEY( "Product service system*" OR "product/service system*" OR "Product-service system*" OR "PSS" OR " functional product*" OR "total offer" OR "servitization" OR "servitisation" OR "integrated solution*" OR "Hybrid offering*" OR "product service bundle" OR "Availability based Contract" OR "integrated logistic support" OR "full-risk contract" OR "performance base logistics" OR "outcome base contract" AND "cost assessment" OR "cost calculation" OR "cost estimation" OR "cost engineering" OR "life cycle cost" OR "cost forecast")

To ensure that only relevant articles entered the pool of papers to be finally analysed, a list of publication-based and content-based inclusion/exclusion criteria was proposed. Only papers published as journal articles or in conference proceedings were selected for the analysis. These contribution types are considered to provide an accurate and representative picture of relevant scholarly research, both shaping the theoretical and empirical work in the field and setting new horizons for inquiry within their frame of reference.

As for the content, articles that did not explicitly deal with cost engineering for PSS were discarded as they were considered to fall outside the scope of the analysis. The key inclusion criteria for selection at this stage were: (1) having PSS at the core of the research (i.e. either presented in the problem description, in the objective of the paper or as a keyword), and (2) explicitly referring to cost engineering methods/tools in the result and/or discussion section of the paper. To ensure completeness, the systematic approach was complemented by snowballing (Wohlin, 2014). Firstly, additional contributions from the same authors were searched to identify the application of the proposed cost engineering method in different case studies. Once found, it was decided to keep in the records only the first original contribution, while the subsequent applications were discarded. Furthermore, the selected articles were checked for possible relevant work cited in their reference list.

\section{PSS cost engineering: insights from the systematic literature review}

As explained in section 2.1, the scope of the systematic literature review was limited to scientific contributions explicitly dealing with the notion of PSS. Hence, a consistent amount of papers produced between the 1960s and the 1990s was excluded, because the servitization phenomenon was poorly studied ate the time. The decision to exclude methods and tools for product life cycle cost is grounded on considerations related to the new objectives and interpretation of the cost analysis task introduced by the PSS mindset. As highlighted by Asiedu and Gu (1998) in their review, most of the life cycle cost models proposed in the nineties were developed for use in "specific phase of the product life cycle, or for specific operations in a particular life cycle phase" (Asiedu and $\mathrm{Gu}, 1998$ p. 897). Similarly to the life cycle cost models introduced in the 1960s by the US Department of Defense to set "design-to-cost" target for effective procurement (Shields and Young 1991), they treated only those cost variables that the designers could directly control, while considering the assessment of the "total cost" of a product as a managerial issue (Asiedu and $\mathrm{Gu}, 1998$ ). Furthermore, the early models developed 
to approach the analysis at the system level, including a service and end-of-life perspective (e.g. Gershenson and Ishii, 1993; Navin-Chandra, 1993), used parametric costing techniques within very restricted areas of application. Such techniques answered to the need of reducing financial losses in operation and support, by minimizing maintenance actions and therefore service-related costs of a product (Asiedu and $\mathrm{Gu}$, 1998).

However, PSS design shall not aim for service cost minimization but rather to the creation of value (Isaksson et al., 2009). This moves the focus of life cycle cost analysis from the minimization of the cost of ownership of a product to the perception of service and maintenance cost as "design variable" to trade-off with product features and performances. This encompasses the possibility for an increased frequency of service and replacement of the hardware (with a possible increase in maintenance and service costs) to grant higher value for the customer, for instance through up-to-date performances or higher focus on the company core business (Alonso-Rasgado et al., 2004). Although recognizing that some of the methods for PSS cost engineering have their roots in previous literature on life cycle costing, such shift in purpose was the reason for confining the systematic literature review to the research field of PSS, and to picture PSS cost engineering approaches at a more granular level.

The search string presented in section 2.1 retrieved 70 research contributions from the Scopus database, which were further reduced to 19 after applying content-based inclusion and exclusion criteria and snowballing. Table 1 presents the final list of contributions from the literature review. It further categorizes them based on the nature of the data and the type of analysis applied, according to the four categories proposed by Erkoyuncu et al. (2009):

- Estimating by Analogy, based on cost from previous similar projects;

- Activity-Based Costing ( $\mathrm{ABC}$ ), identifying activities and allocating their cost based on actual consumption;

- Parametric Methods, predicting cost as functions of basic attributes using e.g. regression, fuzzy logic, and neural network; and

- Extrapolation, using experience to inform projections on future costs.

Table 1. Categorization of cost engineering approaches for PSS design

\begin{tabular}{|c|c|c|c|c|c|}
\hline Reference & Method & $\begin{array}{l}\text { Approach for } \\
\text { cost } \\
\text { estimation }\end{array}$ & Description & Benefits & Drawbacks \\
\hline $\begin{array}{l}\text { Sandberg et } \\
\text { al., } 2005\end{array}$ & $\begin{array}{l}\text { Life cycle } \\
\text { simulation } \\
\text { Model }\end{array}$ & $\begin{array}{l}\text { Parametric } \\
\text { methods }\end{array}$ & $\begin{array}{l}\text { Couples the } \\
\text { geometry } \\
\text { definition } \\
\text { process to the } \\
\text { cost estimation } \\
\text { activity. }\end{array}$ & $\begin{array}{l}\text { - Proposed an automatic } \\
\text { generation of life cycle } \\
\text { cost indication in } \\
\text { conceptual design. }\end{array}$ & $\begin{array}{l}\text { - Features simplified cost } \\
\text { drivers. } \\
\text { - Needs extended knowledge } \\
\text { to be acquired to formulate } \\
\text { the rules. }\end{array}$ \\
\hline $\begin{array}{l}\text { Kreye et al., } \\
2009\end{array}$ & $\begin{array}{l}\text { Game Theory } \\
\text { in TLC }\end{array}$ & $\begin{array}{l}\text { Estimation by } \\
\text { analogy }\end{array}$ & $\begin{array}{l}\text { Game Theory is } \\
\text { used to model } \\
\text { the cost } \\
\text { uncertainty in } \\
\text { the life cycle. }\end{array}$ & $\begin{array}{l}\text { - Deals with uncertainty } \\
\text { considering decision } \\
\text { makers individual } \\
\text { perception. }\end{array}$ & $\begin{array}{l}\text { - Needs further development } \\
\text { and validation. } \\
\text { - The comprehensibility of } \\
\text { the models can be an issue. } \\
\text { - Does not describe any } \\
\text { application in real cases. }\end{array}$ \\
\hline
\end{tabular}




\begin{tabular}{|c|c|c|c|c|c|}
\hline $\begin{array}{l}\text { Zhang et al., } \\
2011\end{array}$ & $\begin{array}{l}\text { IDEF0 for } \\
\text { PSS cost } \\
\text { modeling }\end{array}$ & Not classifiable & $\begin{array}{l}\text { IDEF0 } \\
\text { modeling is } \\
\text { used to assess } \\
\text { the } \\
\text { environmental } \\
\text { impact and cost } \\
\text { of PSS. }\end{array}$ & $\begin{array}{l}\text { - Integrates sustainability } \\
\text { and cost aspects in a } \\
\text { unique model. }\end{array}$ & $\begin{array}{l}\text { Does not address the issue } \\
\text { of availability of data. } \\
\text { - Theoretical application with } \\
\text { no real case application. }\end{array}$ \\
\hline $\begin{array}{l}\text { Kimita et al., } \\
2012\end{array}$ & $\begin{array}{l}\text { Process } \\
\text { Simulation } \\
\text { method for } \\
\text { PSS design }\end{array}$ & $\begin{array}{l}\text { Activity Based } \\
\text { Costing }+ \\
\text { Parametric } \\
\text { methods }\end{array}$ & $\begin{array}{l}\text { Apply ABC and } \\
\text { Scene } \\
\text { Transition Nets } \\
\text { to predict } \\
\text { service cost } \\
\text { using statistical } \\
\text { distributions. }\end{array}$ & $\begin{array}{l}\text { Provides a distribution } \\
\text { curve of simulated service } \\
\text { costs. }\end{array}$ & $\begin{array}{l}\text { - Is mainly service-oriented. } \\
\text { - Needs the identification of } \\
\text { stochastic elements within a } \\
\text { service. } \\
\text { - Uncertainty on the } \\
\text { variability of cost drivers. }\end{array}$ \\
\hline $\begin{array}{l}\text { Romero Rojo } \\
\text { et al., } 2012\end{array}$ & $\begin{array}{l}\text { Obsolescence } \\
\text { model }\end{array}$ & Extrapolation & $\begin{array}{l}\text { A cost } \\
\text { estimating } \\
\text { framework for } \\
\text { the Electrical, } \\
\text { Electronic and } \\
\text { Electromechanic } \\
\text { al components } \\
\text { obsolescence. }\end{array}$ & $\begin{array}{l}\text { - It accounts for risk } \\
\text { assessment and alternative } \\
\text { obsolescence resolution. } \\
\text { - Deals with uncertainty in } \\
\text { cost estimation through } \\
\text { Monte Carlo simulations. }\end{array}$ & $\begin{array}{l}\text { - Is limited to cost estimation } \\
\text { of obsolescence. }\end{array}$ \\
\hline $\begin{array}{l}\text { Settanni et } \\
\text { al., } 2014\end{array}$ & $\begin{array}{l}\text { TLC for } \\
\text { advanced } \\
\text { services }\end{array}$ & Extrapolation & $\begin{array}{l}\text { A methodology } \\
\text { is proposed } \\
\text { encompassing } \\
\text { the definition of } \\
\text { functional units, } \\
\text { scope, } \\
\text { boundaries and } \\
\text { Knowledge } \\
\text { Elicitation }\end{array}$ & $\begin{array}{l}\text { Provides a detailed } \\
\text { analysis of shortcomings } \\
\text { and future research } \\
\text { directions for TLC applied } \\
\text { to PSS. }\end{array}$ & $\begin{array}{l}\text { Requires information } \\
\text { transparency between } \\
\text { customer and provider. } \\
\text { - Does not provide any } \\
\text { example of application in a } \\
\text { real case. }\end{array}$ \\
\hline $\begin{array}{l}\text { Goncalves } \\
\text { and } \\
\text { Kokkolaras, } \\
2015\end{array}$ & $\begin{array}{l}\text { Value-driven } \\
\text { modeling }\end{array}$ & $\begin{array}{l}\text { Estimation by } \\
\text { analogy }+ \\
\text { Parametric } \\
\text { methods }\end{array}$ & $\begin{array}{l}\text { Approach to } \\
\text { model tactical } \\
\text { and operational } \\
\text { decision for PSS } \\
\text { design using } \\
\text { Quality } \\
\text { Function } \\
\text { Deployment } \\
\text { (QFD) and } \\
\text { Design-to-cost } \\
\text { (DTC) models }\end{array}$ & $\begin{array}{l}\text { - QFD and DTC allow } \\
\text { flexibility. } \\
\text { - Uses DOE to assess the } \\
\text { impact on design variables } \\
\text { on PSS cost. }\end{array}$ & $\begin{array}{l}\text { - Focuses on a limited set of } \\
\text { PSS dimensions. }\end{array}$ \\
\hline $\begin{array}{l}\text { Lindhal al., } \\
2015\end{array}$ & $\begin{array}{l}\text { Life Cycle } \\
\text { Costing }\end{array}$ & $\begin{array}{l}\text { Estimation by } \\
\text { analogy }\end{array}$ & $\begin{array}{l}\text { Quantification } \\
\text { of } \\
\text { environmental } \\
\text { and economic } \\
\text { benefits of a } \\
\text { PSS in } \\
\text { comparison with } \\
\text { traditional sales }\end{array}$ & $\begin{array}{l}\text { Applies established Life } \\
\text { Cycle Assessment and Life } \\
\text { Cycle Costing techniques. }\end{array}$ & $\begin{array}{l}\text { - Describes the findings of } \\
\text { three case studies. } \\
\text { - Requires good availability } \\
\text { of data. } \\
\text { - Does not directly contribute } \\
\text { to the development of PSS } \\
\text { cost models. }\end{array}$ \\
\hline $\begin{array}{l}\text { Sakao and } \\
\text { Lindhal, } 2015\end{array}$ & $\begin{array}{l}\text { Life Cycle } \\
\text { Costing }\end{array}$ & $\begin{array}{l}\text { Estimation by } \\
\text { analogy }\end{array}$ & $\begin{array}{l}\text { Proposes an } \\
\text { Excel and } \\
\text { MATLAB- } \\
\text { based tool to } \\
\text { support } \\
\text { Integrated } \\
\text { Product Service } \\
\text { Offering design. }\end{array}$ & $\begin{array}{l}\text { Expands LCC analysis } \\
\text { process to best fit a PSS } \\
\text { offer. }\end{array}$ & $\begin{array}{l}\text { Requires extended } \\
\text { availability of data. }\end{array}$ \\
\hline $\begin{array}{l}\text { Bonetti et al., } \\
2016\end{array}$ & $\begin{array}{l}\text { Total Cost of } \\
\text { Ownership }\end{array}$ & $\begin{array}{l}\text { Estimation by } \\
\text { analogy }\end{array}$ & $\begin{array}{l}\text { TCO analysis of } \\
\text { Aluminum } \\
\text { Melting } \\
\text { Furnaces. }\end{array}$ & $\begin{array}{l}\text { Applies established } \\
\text { methods for TCO. }\end{array}$ & $\begin{array}{l}\text { - Considers a pure product, } \\
\text { coupled with additional } \\
\text { services } \\
\text { - Limited validation and } \\
\text { generalizability. }\end{array}$ \\
\hline $\begin{array}{l}\text { Marchi et al., } \\
2016\end{array}$ & $\begin{array}{l}\text { Life Cycle } \\
\text { Costing }\end{array}$ & $\begin{array}{l}\text { Estimation by } \\
\text { analogy }\end{array}$ & $\begin{array}{l}\text { Estimation of } \\
\text { operation } \\
\text { condition and }\end{array}$ & $\begin{array}{l}\text { - Proposes a detailed cost } \\
\text { evaluation in absolute } \\
\text { terms. }\end{array}$ & $\begin{array}{l}\text { Requires well-defined } \\
\text { concepts. }\end{array}$ \\
\hline
\end{tabular}




\begin{tabular}{|c|c|c|c|c|c|}
\hline & & & $\begin{array}{l}\text { maintenance } \\
\text { impact on EAF } \\
\text { transformers } \\
\end{array}$ & & $\begin{array}{l}\text { - Requires specific data on } \\
\text { performances and } \\
\text { processes. }\end{array}$ \\
\hline $\begin{array}{l}\text { Seiringer and } \\
\text { Bauer., } 2016\end{array}$ & $\begin{array}{l}\text { Time Driven } \\
\text { Activity } \\
\text { Based } \\
\text { Costing }\end{array}$ & $\begin{array}{l}\text { Activity Based } \\
\text { Costing }+ \\
\text { Parametric } \\
\text { methods }\end{array}$ & $\begin{array}{l}\text { Inclusion of } \\
\text { trust-based risk } \\
\text { factors into } \\
\text { service costing } \\
\text { to improve } \\
\text { service cost } \\
\text { management. }\end{array}$ & $\begin{array}{l}\text { Introduces the } \\
\text { consideration of the } \\
\text { trustworthiness of the } \\
\text { customer input as a risk } \\
\text { factor. }\end{array}$ & $\begin{array}{l}\text { Its focus is limited to } \\
\text { service cost in the context } \\
\text { of PSS. }\end{array}$ \\
\hline $\begin{array}{l}\text { Wilberg et } \\
\text { al., } 2016\end{array}$ & $\begin{array}{l}\text { Data-Driven } \\
\text { proactive cost } \\
\text { management }\end{array}$ & Extrapolation & $\begin{array}{l}\text { A theoretical } \\
\text { framework to } \\
\text { include use } \\
\text { phase data in } \\
\text { cost } \\
\text { management of } \\
\text { PSS. }\end{array}$ & $\begin{array}{l}\text { - Includes in the decision } \\
\text { process data from the } \\
\text { customers' use phase }\end{array}$ & $\begin{array}{l}\text { - Does not support concept } \\
\text { development. } \\
\text { - Does not describe any } \\
\text { application in real cases. }\end{array}$ \\
\hline $\begin{array}{l}\text { Estrada and } \\
\text { Romero, } \\
\text { 2016) }\end{array}$ & $\begin{array}{l}\text { Total PSS } \\
\text { Operational } \\
\text { cost }\end{array}$ & $\begin{array}{l}\text { Parametric } \\
\text { methods }\end{array}$ & $\begin{array}{l}\text { Uses a } \\
\text { probabilistic } \\
\text { method to } \\
\text { determine the } \\
\text { total operational } \\
\text { cost of a PSS. } \\
\end{array}$ & $\begin{array}{l}\text { - It is applicable to any PSS } \\
\text { configuration. }\end{array}$ & $\begin{array}{l}\text { - Focuses on operational } \\
\text { performances. } \\
\text { - Treats functional } \\
\text { performance as a random } \\
\text { variable. }\end{array}$ \\
\hline $\begin{array}{l}\text { Schuh et al., } \\
2017\end{array}$ & $\begin{array}{l}\text { Variety } \\
\text { induced cost }\end{array}$ & $\begin{array}{l}\text { Activity Based } \\
\text { Costing }\end{array}$ & $\begin{array}{l}\text { Consist on a } \\
\text { PSS description } \\
\text { model and PSS } \\
\text { explanatory } \\
\text { model to } \\
\text { visualize variety } \\
\text { and estimate } \\
\text { variety-induced } \\
\text { costs. }\end{array}$ & $\begin{array}{l}\text { It is based on established } \\
\text { methods for Time-Driven } \\
\text { Activity-Based Costing. }\end{array}$ & $\begin{array}{l}\text { Requires extended } \\
\text { availability of data } \\
\text { especially for the cost of the } \\
\text { service features. }\end{array}$ \\
\hline $\begin{array}{l}\text { Shen et al., } \\
2017\end{array}$ & $\begin{array}{l}\text { PSS cost } \\
\text { evaluation } \\
\text { indicator }\end{array}$ & $\begin{array}{l}\text { Activity Based } \\
\text { Costing }\end{array}$ & $\begin{array}{l}\text { A cost } \\
\text { evaluation } \\
\text { approach to } \\
\text { compare the } \\
\text { cost of different } \\
\text { PSS cost } \\
\text { elements among } \\
\text { the feasible } \\
\text { configuration } \\
\text { solutions }\end{array}$ & $\begin{array}{l}\text { - The cost comparison is run } \\
\text { in relative terms, requiring } \\
\text { fewer data and } \\
\text { information. }\end{array}$ & $\begin{array}{l}\text { - It is applicable in case of } \\
\text { high availability of } \\
\text { information. }\end{array}$ \\
\hline $\begin{array}{l}\text { Sun et al., } \\
2017\end{array}$ & $\begin{array}{l}\text { Aero Engine } \\
\text { Overhaul } \\
\text { Service }\end{array}$ & $\begin{array}{l}\text { Activity Based } \\
\text { Costing }\end{array}$ & $\begin{array}{l}\text { Multi-objective } \\
\text { optimization of } \\
\text { service } \\
\text { configuration }\end{array}$ & $\begin{array}{l}\text { Optimizes the } \\
\text { configuration considering } \\
\text { multiple relevant } \\
\text { objectives (including } \\
\text { energy as a proxy of the } \\
\text { environmental impact). }\end{array}$ & $\begin{array}{l}\text { Requires extended } \\
\text { availability of data. }\end{array}$ \\
\hline $\begin{array}{l}\text { Thomsen et } \\
\text { al., } 2017\end{array}$ & $\begin{array}{l}\text { Value } \\
\text { maximization }\end{array}$ & $\begin{array}{l}\text { Parametric } \\
\text { methods }\end{array}$ & $\begin{array}{l}\text { A value- } \\
\text { maximizing } \\
\text { framework for } \\
\text { making } \\
\text { component } \\
\text { lifting decisions } \\
\text { in a PSS } \\
\text { context. }\end{array}$ & $\begin{array}{l}\text { - Quantifies life cycle trends } \\
\text { during early design stages } \\
\text { - Quantifies the maturity of } \\
\text { the knowledge. }\end{array}$ & $\begin{array}{l}\text { Poor availability of data in } \\
\text { an early stage. } \\
\text { - Focuses limited to } \\
\text { manufacturing and repair. }\end{array}$ \\
\hline
\end{tabular}

The selection of the most suitable methods largely depends on the availability of data and on the tupe of the PSS considered. Most of the approaches fall in the 'Estimation by analogy' and 'Activity Based Costing' categories, with recent contribution increasingly focusing on a combination of $\mathrm{ABC}$ and parametric models.

Estimation appears to be the most popular method for PSS cost modelling (Estrada et al., 2017). It is applied in several case studies mostly linked to Life Cycle Costing 
(LCC) and Total Cost of Ownership (TCO) analysis. Major examples of applications of LCC for PSS cost estimation can be found in Lindahl et al. (2014), Sakao and Lindahl, (2015), and Marchi et al. (2016). An example of TCO is proposed by Bonetti et al. (2016) while Kreye et al. (2009) model uncertainty in Through Life Cost (TLC) calculation using Game Theory.

LCC- and TLC-based estimations have been criticized in the literature (see: Kambanou and Lindahl 2016) due to the difficulty of systematically collecting input data for the analysis (Aurich et al., 2010). Customers or supply chain partners might not be eager or capable to share relevant data due to lack of trust, lack of technological support, or absence of motivation for sharing (Datta and Roy, 2010; Kreye et al., 2013). Also, engineers often assume that an optimally designed PSS shall have a cost that is inferior to what obtained by delivering products and services separately. If so, to be reliable, the cost model input shall be different from merely considering data from products and data from services separately. In addition, the lack of research on end-of-life stages (Xu et al., 2012) and the fact that often services are co-created with the customers (Xu et al., 2012; Dorn and Seiringer 2012), increase the uncertainty of LCC evaluation.

Furthermore, Settanni et al. (2014) highlight three gaps when addressing the sociotechnical nature of a PSS: (a) not being able to deal with a system (rather dealing with one cost object at a time), (b) not being able to deal with the cost and performance evolution during the course of actions within and across organizational boundaries, and (c) not being able to attribute specific cost to specific activities. To cope with this gaps they propose a methodology based on extrapolation that renders an integrated system cost model based on value delivering flow, using monetary metrics as a meta-language to express the flow of goods and services). Similarly, the work by Romero Rojo et al. (2012) proposes a framework to estimate the non-recurrent costs of obsolescence of a PSS during its contractual period, applying Monte Carlo simulation to deal with the intrinsic uncertainty of the cost estimation. More recently Wilberg et al. (2016) have proposed a theoretical framework for data-driven proactive cost management that encompasses the extrapolation of data from the customer use phase for the management of a PSS.

Estrada and Romero (2016) suggest moving from cost estimation to real cost engineering to reduce the uncertainty in PSS costing. In this spirit, they propose a parametric model to calculate the total PSS operational cost based on a probabilistic method, later applied by Estrada et al. (2017) on a bike sharing system. Parametric methods for PSS cost modeling have also been applied in aerospace design. An early approach from Sandberg et al. (2005) couple CAD geometry definition with a cost estimation activity. More recently Goncalves and Kokkolaras (2015) propose a model to support tactical and operational decisions based on the quantification of customer value and design cost, with the latter being obtained using regression analysis combined with estimations. They further conduct design of experiment to study cost fluctuations caused by variation of PSS design decisions, visualizing the result through spider diagrams and response surfaces. Furthermore, Thomsen et al., (2017) propose a valuemaximizing framework for making component lifting decision in the context of aerospace PSS design. 
The Time-Driven Activity-Based Costing method proposed by Seiringer and Bauer (2016) exploits statistical analysis in combination with ABC. Similarly, Kimita et al. (2012) combine ABC with parametric modeling, using Transition Nets to predict service cost using statistical distributions. An extensive model based on ABC is proposed by Shen et al. (2017), encompassing a preparatory stage, an evaluation stage, and a configuration stage. However, the framework is applied at a configuration stage, which implies the PSS to be mature enough to provide a high availability of information (Shen et al., 2017). Further applications of ABC for PSS cost modeling are described by Schuh et al. (2017), who introduce a method to evaluate the variety-induced costs in PSS. Sun et al. (2017) further propose a multi-objective optimization approach for the configuration of aero-engine overhaul services. Yet, both methods require the availability of an large amount of data to be meaningfully executed.

As a general conclusion, the review highlights that, since PSS simultaneously encompass multiple, interconnected and interacting cost objects, focusing on a single cost object at a time does not provide an appropriate estimation (see also: Settanni et al. 2014). This challenge is emphasized because services are often enabled by technical solutions, enhancing the use or availability of the products for a long life-cycle (Durugbo, 2014), and such long-life cycles imply high uncertainty in the PSS performances (Shen et al., 2017).

From the point of view of sub-system design, the literature review revels that there is no well-established approach to estimate the cost of PSS along its life cycle. The Design to Cost model by Goncalves and Kokkolaras (2015) takes a step toward identifying PSS design alternatives to deliver value to the customer. The logic of their approach is the most similar to the one presented in this paper, although missing some of the key features presented in section 5 and exemplified in section 6.

\section{Descriptive study findings: capabilities for PSS cost engineering}

The Descriptive study findings brought to the identification of contextual factors and desired capabilities that need to be accounted for when developing PSS cost engineering in sub-system design. Throughout the study, empirical evidence shows a preference towards cost engineering methods able to link the geometrical and physical characteristics of the hardware to a monetary measure of 'design goodness'. In this respect, the ability to evaluate the fit-for-purpose of different product platform variants for PSS was spotlighted as main capability in concept design. Furthermore, cost metrics shall be able to encompass both tangible and less tangible dimensions, as well as to highlight the difference against a given baseline configuration. These high-level findings are detailed in the following subsections.

\subsection{Supporting the evaluation of platforms variants}

In Systems Engineering, new sub-systems or product components are seldom radically new designs. The necessity to comply with many requirements cascaded down from the system integrators means that design freedom is often confined to a limited set of 
engineering characteristics for a given product platform (Monceaux et al., 2014, Isaksson et al., 2013). Platforms play a significant role in the successful management of family products, being introduced to enable re-use of technologies, product design solutions and production system solutions. Being able to manufacture product variants based on a common platform and modular architecture is considered to be of strategic advantage. It gives the ability to use components, design solutions and processes to reach economies of scale and capture the knowledge produced through all these activities and interactions (Vallhagen et al. 2013; Levandowski et al. 2014). Together with generic guidelines and specific requirements/constraints, a product platform encompasses also a production platform. The latter contains a concise representation of the targeted production system, whose requirements shall be considered already in the concept design phase (Vallhagen et al., 2013). Hence, the aim of concept selection activities in PSS design becomes often that of assessing the feasibility and fit-forpurpose of different hardware configurations, rather than that of assessing radically new solutions.

\subsection{Enabling an iterative, set-based engineering approach}

A stage-gate process (Cooper, 2008) is widely adopted in industry (Johansson et al., 2011) to guide product development activities. In this process, set-based concurrent engineering (Sobek et al., 1999) has been introduced to exclude non-viable and nonsustainable solutions as opposed to selecting and refining the best concepts. Deploying set-based engineering presumes evaluation of several 'points' in the design space. This is done either through evaluation of a certain solution for a range of conditions or benchmarking of several solution variants for different situations (Vallhagen et al., 2013). Set based engineering is composed of 2 main value streams (Kennedy et al., 2008). The Knowledge Value Stream (KVS) represents the systematic building of knowledge over time; whereas the Product Value Stream (PVS) represents the process to make efficient use of available knowledge (from KVS) once a target product application (most often technologies and components for new engine development) has been initiated.

Empirical data support previous observations (e.g. Isaksson et al., 2015; Bertoni et al., 2015), showing that the assessment of platform variants in the KVS is mainly supported by qualitative and semi-quantitative models. Cost engineering is not a preferred benchmarking mechanism at this stage. A requirement for KVS models is to withstand situations where the information available is scarce, immature and incomplete. Also, these models serve mainly the purpose of communicating opportunities for value creation, rather than of rendering detailed aspects of cost (Bertoni et al. 2016).

\subsection{Exploiting an analogous approach for cost engineering}

Entering in the PVS stage, life cycle cost models become appealing to raise awareness on the economic impact of alternative design concepts in the customer operational process. These models are iterated as long as the product description evolves, and data 
may be obtained from increasingly refined functional and analytical models.

Operational performances (e.g., use of resources or output quality) and operational support (e.g., downtime or maintainability) are the most immediate cost items to be considered at this stage. Still, when quantitative models are approached for the first time, the design space is dominated by information volatility. For this reason, initial quantitative value models have been found to insist on a conceptual approach (Gupta, 1983), which consists of a set of hypothesized relationships expressed in a qualitative framework. Experts and practitioners also emphasized the benefit of an analogous approach (Feldman and Shtub, 2006) to Total Cost of Ownership modelling, due to the product 'type' to be engineered. The analogous approach was believed by several respondents to be the best fit at this stage, as it facilitates benchmarking between innovative platform configurations based on similarity vs. existing solutions and platform baselines. However, a deeper analysis reveals a widespread preference towards applying a top-down revenue model build on a parametric approach (Feldman and Shtub, 2006). In this spirit, cost estimates shall be constructed basing on previous experiences with the product, using historical data and lessons learned from previous projects to estimate expected revenues.

\subsection{Enabling the relative benchmarking of available design options}

The empirical study highlighted a preference towards rendering a relative measure of cost, rather than an absolute monetary figure of cost for each platform variant. The latter is advocated to be an extremely complex challenge in the early stages of the PSS design process. The countless number of factors that concur to determine the final cost are unknown or undefined in concept design. Nevertheless, engineers asked to make decisions amongst different design configurations might not need to know precise figures, rather they expressed a need to be able to benchmark alternative designs in relative terms, spotlighting the ones that would render higher or lower costs compared to a reference design. This suggests adopting a logic of relative comparison in the development of the PSS cost engineering approach, where the cost of alternative design variants is estimated only taking into consideration those variables that are foreseen to cause a sensible change in the final cost structure. This approach goes hand in hand with the product platform strategy. The latter significantly limits design freedom of new subsystems concepts, due to the need of complying with well-established requirements for integration into the overall system. This facilitates a direct cost comparison between design options, because hardware implying radical architectural changes are often not feasible.

\section{PSS life cycle cost engineering for sub-system design: logic of the model-based approach}

The Prescriptive Study brought to the definition of a cost engineering approach built on a modular structure based on the principle that the output of the cost model shall be expressed as the positive (or negative) difference between a given design and a baseline. 
This cost model is built, in turn, by linking together several cost sub-models which refer to different areas of interest for the PSS.

Furthermore, the cost engineering approach is model-based, which is it receives as input the results of early stage simulations (e.g., computational fluid dynamics, finite element analysis, and more) conducted on the available geometrical description or hardware. To automate the evaluation of several design cases, a product platform is described using a parametric 3D CAD model. Figure 2 summarizes the steps of model-based approach and the logical flow between the different models.

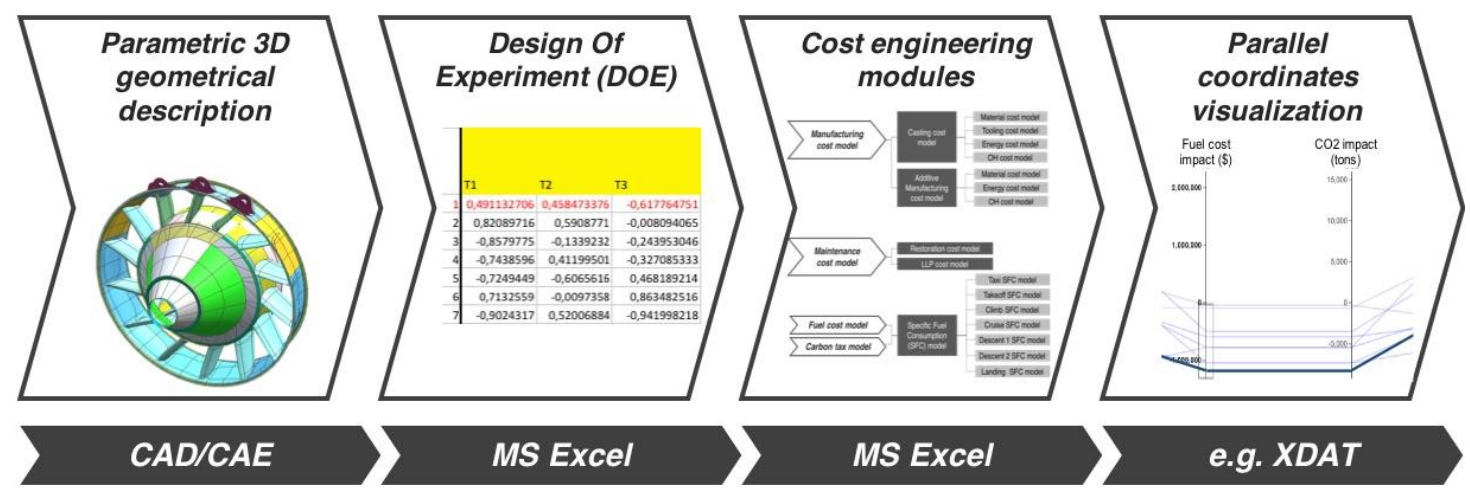

Figure 2. Logical flow of the model-based PSS cost engineering approach.

The generation of relevant platform variants is based on the use of a Design of Experiment routine. DOE is a technique for choosing a limited set of data samples in the design space with the goal of maximizing the amount of information produced (Giunta et al., 2003). When the CAD model of the platform is available, design parameters intended to be selectable as design variables in the DOE are defined, and engineers select which of them shall be included in the DOE study.

After selecting the variables and their bounds, engineers use an appropriate sampling technique to generate the experimental plan. When the experiment is executed, associated attributes for all platform variants in the plan are predicted and stored in a database. At this stage, relevant cost assessment modules need to be selected based on the objectives of the specific development cases, or on the description of the specific PSS usage scenario under investigation. The approach adopts the generic modules for the calculation of the Total Cost of Ownership of a PSS proposed by the PROTEUS Tool book (Finken et al. 2013). The level of priority of each module is tuned for each specific case, based on the analogy with previous projects on similar product platforms. Noticeably, the simultaneous calculation of different cost modules for each design case can generate a consistent amount of data. Hence, visualization support is needed to navigate the data set and perform trade-off analysis. Decision makers shall be able to identify a limited set of design cases that satisfy specific cost and performance requirements, so to be able to run more detailed design analysis on a restricted number of platform variants, if needed. The approach prescribes the use of parallel coordinates to highlight cost and other performances associated with the different design cases. The visualization works as an interactive tool allowing the selection of those cases satisfying specific requirements defined by the engineers, in terms of both mechanical and life cycle cost and performances. 
The transfer of input and output from a calculation to another is managed through the use of a commercial CAD software and computational spreadsheets (i.e. Microsoft Excel in the proposed case study implementation).

\section{Application of the approach to a commercial aircraft engine component}

The model-based approach presented in Figure 2 was implemented in a case study related to the development of a turbine rear structure (TRS) for commercial aircraft engines.

\subsection{About the case study company and its transition towards PSS}

The case company is active on the global market as a design-make supplier to major aero-engine Original Equipment Manufacturer (OEM). It is active in various product and technology development projects, mainly for gas turbines, aircraft, and rocket engines. It also offers aviation services such as leasing, logistics and inventory management, including overhaul and repair of aircraft engines. The company functions as an independent risk and revenue sharing partner, and assumes responsibility for certain engine components, from development, design, and manufacturing, to repair and maintenance services throughout the entire lifetime of an engine type.

The long lifespan of a commercial aero-engine and safety considerations create the need for regular maintenance operations, ultimately leading to large investments for monitoring and predicting components life to provide spare parts prior to failure (Ward and Graves, 2007). Hence, aerospace OEM, have increasingly focused their attention toward the possibility to provide product-related services in their business offer (Baines et al., 2009; Wallin, 2013; Wallin et al., 2015). This paradigm shift has deep consequences for engineering designers. Traditionally the design of aero-engine components has been driven by airlines expectations to improve performances, while reducing fuel consumption and $\mathrm{CO}_{2}$ production. This is obtained by minimizing weight, by allowing higher temperatures to be reached in the core of the engine, and by enabling a larger bypass ratio. The transition towards service-based business models enforces a through-life engineering view, stressing the importance of functionality and availability in service aspects compared to a traditional one-sale model (Vallhagen et al. 2013). This leads to an increased emphasis on the monetary assessment of availability-related aspects, including inspections, service interventions, engine upgrades (Vallhagen et al.; 2013), which cascade down to dimensions such as lead time for assembly and disassembly of components.

\subsection{Application of the model-based cost engineering approach for TRS design}

Figure 3 displays the cost items were considered priorities, negligible or not assessable when developing the model-based approach for the TRS. These items mirror the TCO cost modules for PSS proposed by Finken et al. (2013), yet not all of them were found to be relevant in the proposed case study. The cost breakdown structure highlights fuel 
cost, manufacturing, and maintenance as main cost modules, which are complemented by a fourth model related to the direct costs associated to the introduction of environmental legislation, such as a carbon tax. These areas were further cascaded down to a series of models to generate the necessary data for the cost modules to be populated. At the same time, other cost areas were considered negligible in the evaluation, because of the poor significance that changes in platform configurations have at the system level.

This prioritization activity was conducted in collaboration with process owners and expert at the case company, based on historical information from previous TRS development projects. The priority areas highlighted in Figure 3 were further verified through interviews and workshops at the case company, involving a cross-disciplinary team of experts in product development methods, engine architecture integration, sustainable product development and manufacturability assessment. The shortlisted set of priority areas is specific for the case study under investigation and might differ from other aerospace sub-system development efforts.

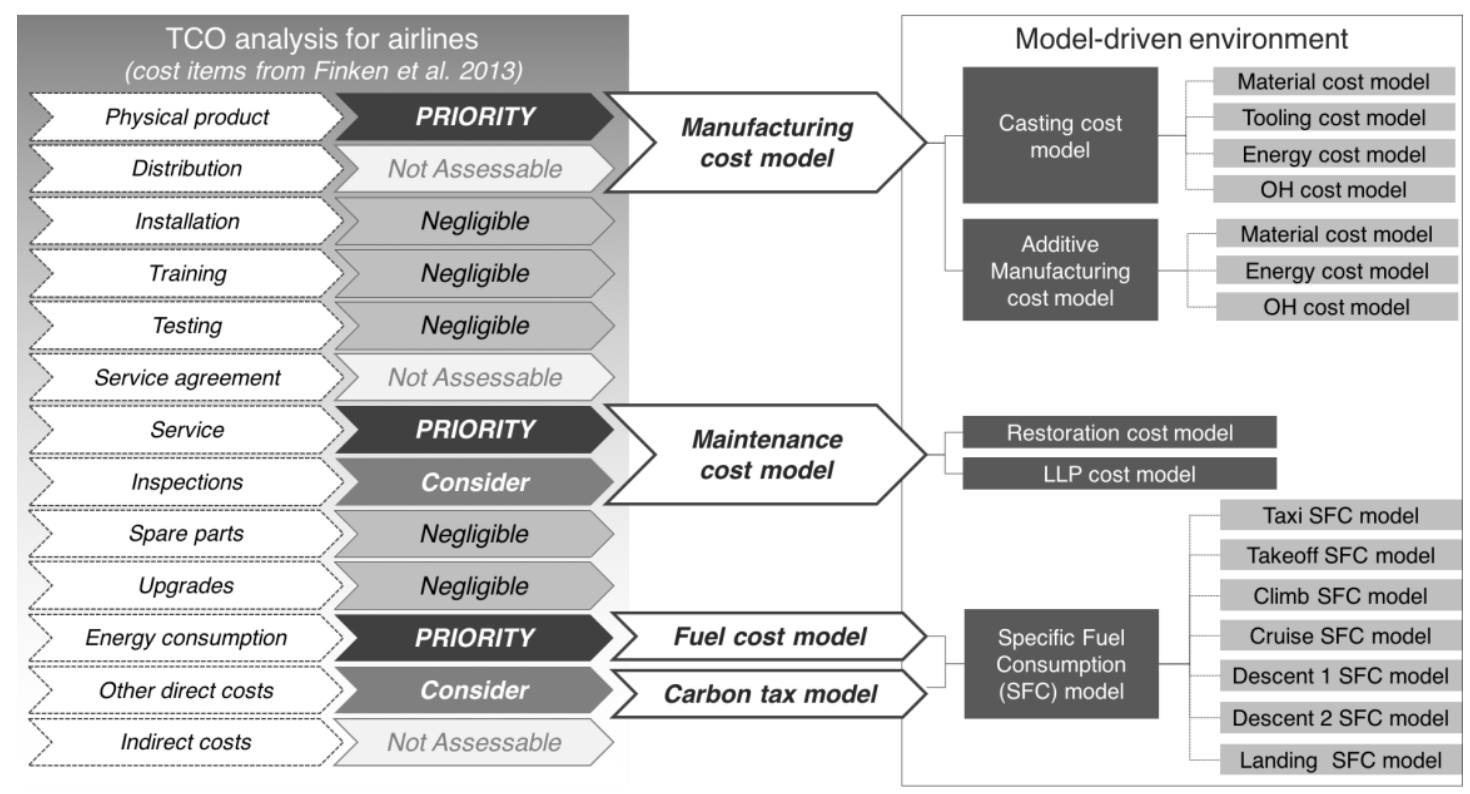

Figure 3. Relevant cost modules and their breakdown structure as applied in the case study (TCO = Total Cost of Ownership; SFC = Specific fuel consumption; LLP = Life Limited Parts;).

After having defined the structure of priorities, the first step in the approach consisted in gathering input from CAE simulations to populate the models. A parametrized CAD model was developed and used to test several design configurations.

Through DoE, an experimental plan was generated containing a total of 128 TRS platform variants. These were simulated and the results were exported in a Microsoft Excel environment. The variables obtained from the simulation for each single design case encompassed, among others, component mass and geometry, the thermal areas, the length, thickness and life of the welding. These data were used as input for the life-cycle cost assessment of the different design cases. Each cost module is briefly described in detail in the following subsections, describing how the operational scenarios have been modelled and how the results form CAE simulation are integrated into the life cycle 
cost assessment. It shall be noted that company-specific data have been artificially modified (e.g., being scaled up or down) due to confidentiality.

\subsection{Scenario description module}

A major requirement for a PSS cost engineering support tool is to be able to immediately quantify the impact of foreseeable changes in the operational scenario. Decision makers shall be able to vary the key driving parameters describing the scenario and calculate the cost for a given design configuration in the new context. Figure 4 shows a screenshot of the scenario description input interface featured by the cost model in MS Excel.

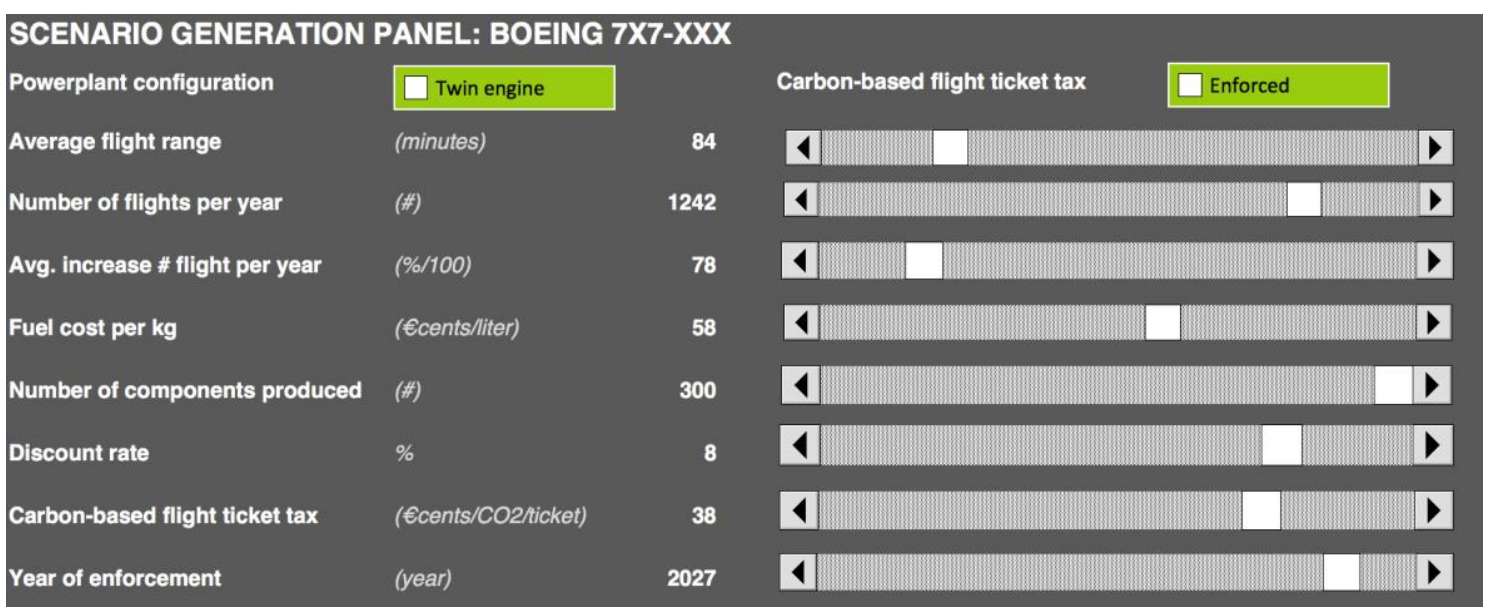

Figure 4. Input interface for scenario generation.

The input interface for scenario generation is purposefully streamlined, featuring a limited set of key parameters. Company respondents showed a preference toward transparent and intuitive means to play with scenario generation, to increase participation and dialogue with non-experts during gate meetings. This suggested to limit the number of factors displayed to the team, as well as to opt for the use of scrollbars as an intuitive means for interacting with the cost models.

Figure 4 (first column) lists the scenario variables having an impact on the life cycle cost assessment for TRS variants, given a Boeing-type aircraft. These include average flight range, the number of flights per year, the number of engines (with direct impact on the fuel cost model), the expected number of components to be produced and the discount rate for the different cash flows in the model. Additionally, the interface allows decision makers to consider scenarios where a carbon-based flight ticket tax in enforced, tuning the year of enforcement. The second column and the third column show respectively the unit of measurement and the actual value of the variables. Each variable is then linked to a scrollbar (fourth column) to enable the interactive modification of the actual value by the user. The definition of alternative scenarios allows the trade-off of the value of different product designs mitigated by potential variations in their operational environment. 


\subsection{Fuel cost model}

The first cost estimation model developed in the case study aimed at evaluating the impact of a design configuration in terms of fuel saved throughout the entire life cycle of the aircraft. In general, aircraft fuel consumption is found to be directly proportional to weight, thus the TRS mass was the main variable considered in the calculation. The model includes a system of weight reduction multipliers to project the impact of a weight reduction of a component on the overall weight of the aircraft. This is because in many situations it can be assumed that reducing TRS weight have cascading effects on the design of other sub-systems, due to better balancing or higher robustness. Therefore, a one-kilogram reduction in the TRS might lead to several kilograms weight reduction at engine level. A 'Factor on whole engine weight reduction' was implemented in the model, and later considered in relation to the number of engines mounted on the aircraft. The same logic was applied in setting a 'Factor for wing weight reduction' aiming to model the kilograms saved on the wings enabled by a lighter engine (e.g. due to the new center of gravity or mounting points). Similarly, a 'Factor on overall aircraft weight reduction' was added. A rule expressing the relation between weight reduction and reduction in fuel consumption was further derived from the work by Yutko (2011), who estimated a $0,75 \%$ reduction in fuel consumption for each $1 \%$ reduction of the total weight of an aircraft.

To predict fuel consumption performances of a new design, the aircraft weight reduction needed to be further calculated as a percentage of the aircraft weight. The Airbus A380 (introduced in 2007) and the Boeing 787 Dreamliner (introduced in 2011) were used as references in this calculation. While embedding state of the art performances, they have been operating long enough for reliable fuel consumption data to be available. Data about the Aircrafts Empty Weights (AEW) were derived from the official technical descriptions (Airbus, 2016; Boeing, 2015). Regression analysis was applied on the official data from the International Civil Aviation Organization (ICAO) (ICAO, 2017) to derive functions approximating the fuel consumption of an aircraft model based on the flight range. Figure 5 shows the data point obtained from the ICAO document about an Airbus A380 and visualizes the fuel consumption function obtained from the regression analyses. 


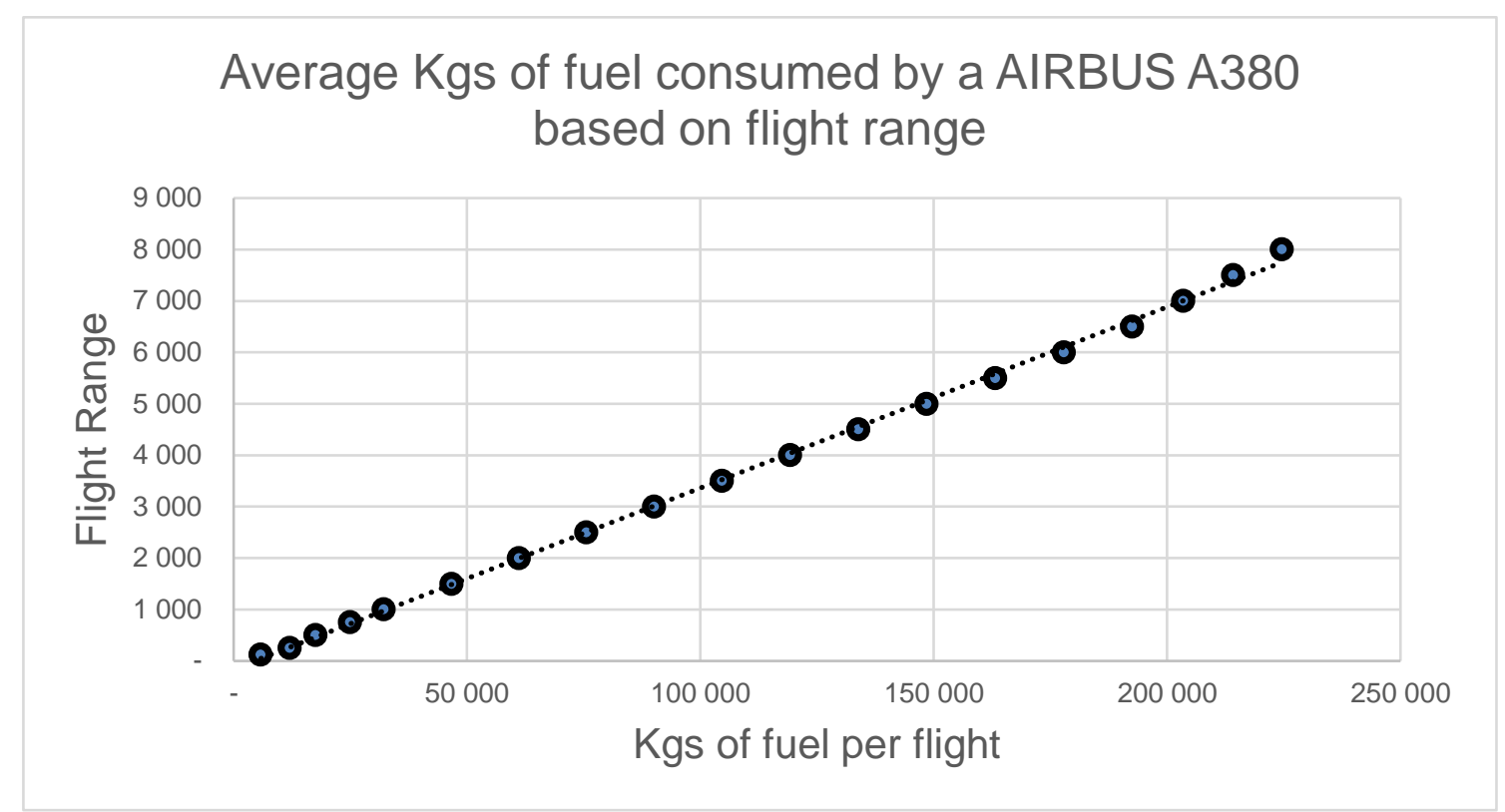

Figure 5. Estimation of the average kilograms of fuel burned by an AIRBUS A380 based on flight range.

Concurrently, the reduction (expressed in \%) of the AEW based on the mass reduction given by each single design case was computed, obtaining a total empty weight reduction (also expressed in \%). From this, the percentage of fuel consumption reduction was obtained by multiplying the percentage of weight reduction by the $75 \%$ fuel reduction factor introduced before.

The fuel saved per flight was then multiplied for the number of flights in the component life (approximated as equal to the number of cycles), this rendered a cost estimation of the fuel cost saving in the product life. The life of an aircraft engine component is traditionally calculated in flight cycles, with a cycle including the various flight segments that describe a complete flight, i.e. start, idle, taxi, takeoff, climb, cruise, approach, landing (FAA, 2009). An assessment of the average expected life of the components was based on established product experience in the aerospace sector, thus setting the life to an average of 10.000 cycles.

A reference baseline was selected from the simulated design cases and the cost estimations were run based on improved or worsened performances in relation to the baseline. Given the comparative nature of the assessment, there was no reason to select a specific baseline instead of another thus this was set by default on Design Case 1 . Table 2 shows an extract of the cost model based on the Airbus A380, showing how 6 randomly chosen design cases score against the baseline. Looking at the 'Delta fuel cost in product life' column, Design Case 7 is estimated to render a saving of about 600.000 dollars along the component life compared to what would be obtained by the baseline. Conversely, Design Case 2 is believed to generate additional costs up to about 222.000 dollars along the product life cycle, compared to the baseline.

Table 2. Extract of the fuel cost assessment model 


\begin{tabular}{|c|c|c|c|c|c|c|c|c|}
\hline \multirow{3}{*}{$\begin{array}{r}\begin{array}{c}\text { Design } \\
\text { case }\end{array} \\
2 \\
\end{array}$} & \multirow{3}{*}{\begin{tabular}{|c} 
TRS Weight variation \\
from baseline (design \\
case 1 ) in Kgs
\end{tabular}} & \multirow{3}{*}{$\begin{array}{c}\begin{array}{c}\text { Overall weigth } \\
\text { variation after } \\
\text { multipliers }\end{array} \\
103,00 \\
\end{array}$} & \multicolumn{6}{|c|}{ Airbus A380 } \\
\hline & & & \multirow{2}{*}{\begin{tabular}{|r|}
$\begin{array}{l}\text { Delta fuel } \\
\text { consumption in } \\
\text { mission } \mathbf{( K g )}\end{array}$ \\
49,28 \\
\end{tabular}} & \multicolumn{2}{|c|}{$\begin{array}{l}\text { Delta fuel } \\
\text { cost per flight }\end{array}$} & \multicolumn{2}{|c|}{$\begin{array}{l}\text { Delta fuel cost } \\
\text { in product life }\end{array}$} & \multirow{2}{*}{ 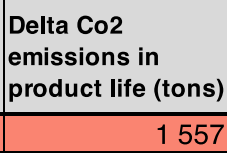 } \\
\hline & & & & $\$$ & 22,24 & $\$$ & 222369 & \\
\hline 3 & $\begin{array}{ll}- & 4,07 \\
\end{array}$ & $-\quad 81,46$ & $-38,97$ & $\$$ & $-17,59$ & $\$$ & -175858 & -1231 \\
\hline 4 & 13,87 & 277,44 & $-132,74$ & $\$$ & $-59,90$ & $\$$ & -598983 & -4194 \\
\hline 5 & 7,70 & 153,92 & $-73,64$ & $\$$ & $-33,23$ & $\$$ & -332308 & -2327 \\
\hline 6 & 3,10 & 61,97 & $-29,65$ & $\$$ & $-13,38$ & $\$$ & -133794 & -937 \\
\hline 7 & 13,98 & 279,51 & $-133,73$ & $\$$ & $-60,35$ & $\$$ & -603450 & -4226 \\
\hline
\end{tabular}

The last column of Table 2, named 'Delta $\mathrm{CO}_{2}$ emissions in product life (tons)', shows the estimation of the tons of $\mathrm{CO}_{2}$ produced by a specific design case compared to the baseline. The data obtained about the kilograms of fuel saved during the product life cycle were multiplied by the kilograms of $\mathrm{CO}_{2}$ produced for 1 kilograms of aircraft fuel burned. Recent data shows that 3.16 kilograms of $\mathrm{CO}_{2}$ are typically produced per kilogram of fuel burned (ICAO, 2017). A positive number indicates an increase in $\mathrm{CO}_{2}$ produced, while a negative number indicates a decrease in its production. In the example, Design Case 7 is expected to save 4.226 tons of $\mathrm{CO}_{2}$ during its life compared to the baseline, while Design Case 2 is expected to produce 1.557 tons more $\mathrm{CO}_{2}$ than the baseline. Although being a quite simplified model, linearly related to weight reduction, the $\mathrm{CO}_{2}$ emission assessment can provide immediate information about the order of magnitude of the sustainability impact that a design decision can generate. The carbon tax cost model was further developed to assess the impact of stricter environmental requirements for airlines' profitability. The overall rationale for implementing such model is that specific taxes on seats, flights, fuel or flight tickets might provide indications about the preferred sub-system configuration when legislation is enforced. Krenek and Schratzenstaller (2016) describe 8 main options for aviation taxes in Europe. Among these mechanisms, a carbon-based flight ticket tax (which is calculated on carbon emissions per flight ticket) was chosen in the cost engineering model to calculate airline revenue and profitability. This choice is based on recommendations from Krenek and Schratzenstaller (2016), which claim that this instrument is one of the most effective to internalize external costs of aviation and to exert incentive for passengers to reduce the number of flights, a major parameter to play with when generating future scenarios.

\subsection{Manufacturing cost model}

The manufacturing cost of each platform variant was calculated based on two alternative manufacturing technologies: casting and additive manufacturing. Even though manufacturing costs are not directly linked to a PSS perspective, decisionmakers showed a preference towards integrating them in the overall cost engineering exercise, to provide a reference point upon which to base trade-off with more life-cycle oriented costs. Noticeably, the performances of the manufacturing machines in the following examples are obtained from the available literature and do not represent the real production capacity and performances of the partner company. 


\subsubsection{Casting cost model}

The casting cost model was developed following the method proposed by Chougule and Ravi (2006). This is composed of four computational sub-modules which address (1) material cost, (2) energy cost, (3) tooling cost and (4) plant and overhead cost.

Material cost encompasses direct and indirect costs related to casting components made of Titanium alloy Ti-6Al-4V (Ti64). The cost per kg for Ti-6Al-4V is multiplied by the mass of the component as obtained from the CAD software. The result is then refined by taking into consideration losses in the manufacturing operations. Three factors for metal loss were considered in the calculation, namely loss in melting, puring, and fettling.

Energy cost in manufacturing is also based on the mass of the components retrieved from CAE environment. The model computes the Kilowatt/hour (KWh) consumed for melting a kilogram of titanium. This calculation considers the efficiency of the furnace, the specific heat of the material for both the solid and the liquid phase, the melting temperature, the room temperature and the pouring temperature. All these input data are calibrated by the design team based on the industrial equipment used. The number of KWh obtained is then multiplied by the unit cost of energy.

Tooling cost is obtained from the method proposed by Chougule and Ravi (2006). It is based on a relative cost of tooling calculated by using the 'cube surface area' of the component in relation to the core complexity. Geometrical data from the CAD models were used to estimate the core complexity and the shape complexity.

Plant and Overhead costs were estimated based on the plant needed for the treatment of Ti64. The cost model receives as input the expected life of the production equipment, the expected life of the controlling software, and the expected number of components produced per year. Activity Based Costing (ABC) was applied to calculate machine cost per year (including maintenance and consumable), utilization rate (based on data about annual machine operating hours), labor cost (based on average salary and number of employee needed), indirect costs related to administration overhead, and facilities occupation cost per year. Table 3 shows an extract of the aggregated casting cost model results for seven of the design cases considered. The data shows the total cost of casting for a single component.

Table 3. Extract from the Casting Cost Model, cost per unit.

\begin{tabular}{|c|c|c|c|c|c|c|}
\hline DESIGN CASE & COST OF MATERIAL & COST OF ENERGY & COST OF TOOLING & PLANT AND OVERHEAD & & $\begin{array}{l}\text { ST OF } \\
\text { VG }\end{array}$ \\
\hline 1 & $\$ \quad 3053$ & $\$ \$ 91$ & $\$ \quad 4263$ & $\$ 99303$ & $\$$ & 16711 \\
\hline 2 & 3172 & 95 & 4266 & 9303 & $\$$ & 16835 \\
\hline 3 & 2960 & 88 & 4261 & 9303 & $\$$ & 16612 \\
\hline 4 & 2735 & 82 & 4255 & 9303 & $\$$ & 16374 \\
\hline 5 & 2877 & 86 & 4259 & 9303 & $\$$ & 16524 \\
\hline 6 & 2982 & 89 & 4261 & 9303 & $\$$ & 16635 \\
\hline 7 & 2732 & 81 & 4255 & 9303 & $\$$ & 16372 \\
\hline
\end{tabular}

\subsubsection{Additive Manufacturing cost model}

A model for estimating the cost of additive manufacturing (AM) was run in parallel with the casting cost model, to allow a comparison of different manufacturing technologies. The model was run considering the case of the whole component being 
manufactured using AM technologies. The AM cost model is composed of 3 submodels, named Material Cost, Energy Cost and Plant and Overhead cost. Material cost was calculated as directly related to the component mass obtained from the CAE environment. Energy cost was calculated by calculating the number of KWh needed to manufacture every single component, given its mass and dimension, and then multiplied by the unit cost of energy. Plant and Overhead cost was obtained following the same process used for casting, tuning its input parameters with regards to machines' purchase costs, their expected life and the number of operators needed. Table 4 shows an extract of the AM cost assessment results for the design cases shown in Table 3.

Table 4. Extract from the Additive Manufacturing cost model,cost per unit.

\begin{tabular}{|c|lr|lr|rr|rr|}
\hline DESIGN CASE & COST OF MATERIAL & \multicolumn{2}{l|}{ COST OF ENERGY } & \multicolumn{2}{c|}{ PLANT AND OVERHEAD } & \multicolumn{2}{c|}{ TOTAL COST OF AM } \\
\hline 1 & $\$$ & 47855 & $\$$ & 26 & $\$$ & 353 & $\$$ & 48234 \\
\hline 2 & $\$$ & 49709 & $\$$ & 27 & $\$$ & 366 & $\$$ & 50102 \\
\hline 3 & $\$$ & 46389 & $\$$ & 25 & $\$$ & 342 & $\$$ & 46756 \\
\hline 4 & $\$$ & 42861 & $\$$ & 23 & $\$$ & 316 & $\$$ & 43200 \\
\hline 5 & $\$$ & 45084 & $\$$ & 24 & $\$$ & 332 & $\$$ & 45441 \\
\hline 6 & $\$$ & 46740 & $\$$ & 25 & $\$$ & 345 & $\$$ & 47109 \\
\hline 7 & $\$$ & 42824 & $\$$ & 23 & $\$$ & 316 & $\$$ & 43163 \\
\hline
\end{tabular}

\subsection{Maintenance cost model}

The maintenance cost model is based on the work of Seemann et al. (2010), who propose a surrogate function to model the life cycle cost of jet engine maintenance. By analyzing a large set of historical data related to maintenance operations in aerospace, Seemann et al. (2010) describe a function that takes as input the 5 parameters believed to influence the maintenance cost of an aero-engine: take-off thrust, dry weight, average flight length, applied derate and environmental conditions. From a sub-system manufacturer perspective, the objective was then to investigate which features of the new design could impact one of those factors, and then estimate the overall impact on the costs. Noticeably, the maintenance cost model considers only off-wing maintenance cost, thus those maintenance activities conducted on the shop floor with the engine detached from the wing. According to Seemann et al. (2010), off-wing maintenance cost are driven by 2 main factors: (1) restoration cost, which depends on the severity of the operational context, and (2) life-limited parts (LPP) cost, which is, instead, independent from the operational severity. The first is best predicted by considering a linear relationship with the take-off thrust of the engine. The second is computed as a function of both take-off thrust and engine weight. Assuming the take-off thrust not being impacted by the design of the TRS, maintenance cost was estimated uniquely based on LPP cost. The weight of the component obtained from the CAE environment for each design case, combined with the multiplier factors presented before, rendered a maintenance cost estimation for each design case.

\subsection{Visualization of the results}

The cost analysis results for the 128 design cases are visualized using parallel coordinates, a type of visualization which allows decision makers to filter the results 
based on the specific performance of the cost targets. As an example, Figure 6 displays those design cases expected to generate savings in fuel cost (column 2) and maintenance cost (column 6) along the life cycle, which are then selected for further analysis. Here, Design case 14 (bold line in Figure 6) is found to be the best in term fuel cost and $\mathrm{CO}_{2}$ emissions reduction. Yet, even though it performs among the bests in term of life cycle maintenance cost, its manufacturing cost for both casting and additive manufacturing are higher than several other design cases.

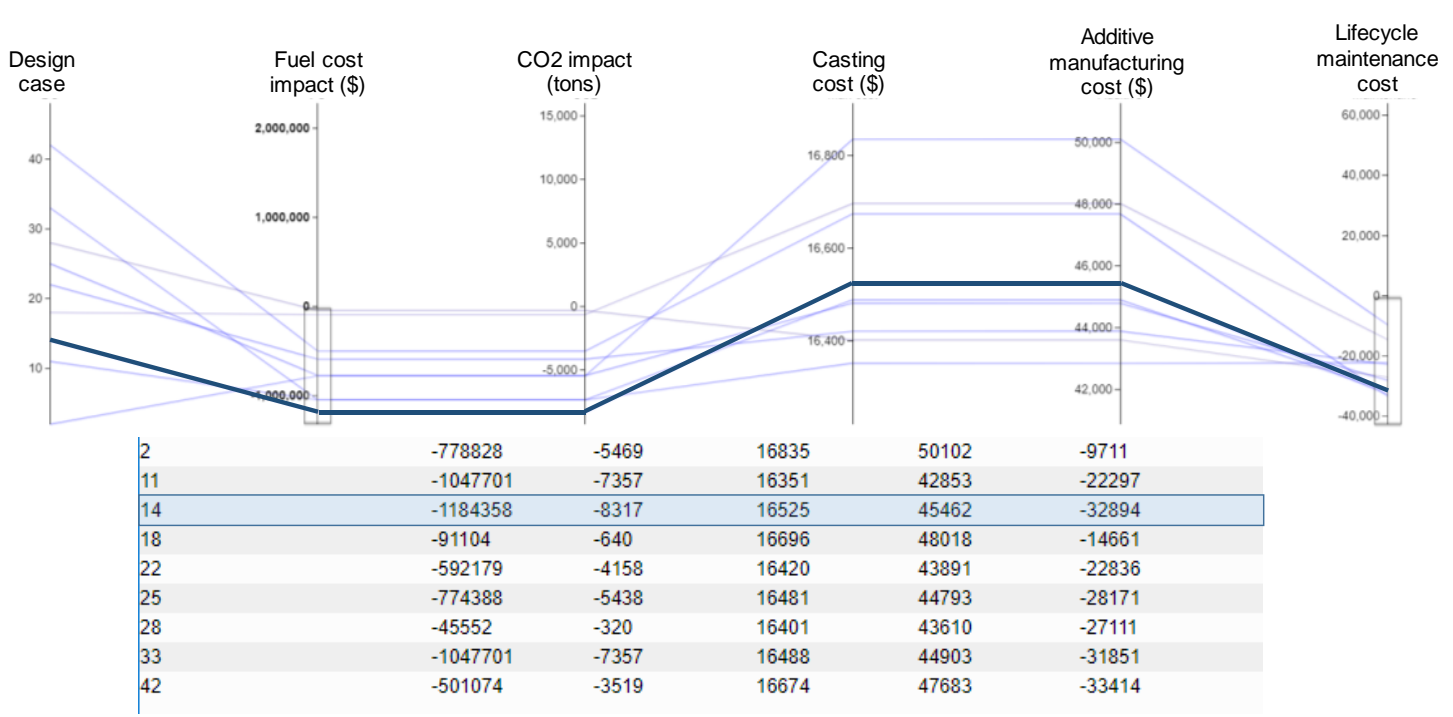

Figure 6: Parallel coordinates visualization of the cost engineering model results

\section{Discussion}

The PSS design process is characterized by high uncertainty and data volatility. Nevertheless, the life cycle costs associated with the PSS hardware is a key criterion for decision makers at gate meetings and constitutes a critical input to reason among design trade-offs. The model-based cost engineering approach presented in this paper was developed to address the industrial need of estimating how a change in sub-system design configuration is reflected on the life cycle cost of the PSS offer. In relation to the categories of cost modelling approaches proposed by Erkoyuncu et al. (2009) (Table 1), the approach is based on the use of parametric methods to predict costs, relying on parameters derived from the CAD/CAE environment using DoE. The approach also encompasses the possibility of applying estimation by analogy for the definition of relevant and neglectable cost modules to be selected from the generic TCO dimensions defined for PSS (Finken et al., 2013). The use of analogy is particularly suitable for subsystems design because of the nature of the hardware to be engineered, that is often based on existing product platforms to ease the integration of new designs into the overall system. This aspect limits the scope of application of the analogy logic to those companies dealing with systems engineering, which is with the incremental innovation of known product platforms.

The model-based approach does not aim to provide an estimation of the cost of alternative designs in absolute terms, rather it renders cost deltas between different 
designs, similarly to what proposed by Shen et al. (2017). This generic structure for cost estimation can be expanded or reduced based on the objective of the analysis, i.e. based on the degree of diversity of the different design alternatives under consideration. Only the modules that are affected by a design change are relevant during the assessment and shall, therefore, be computed. In the case study, from a manufacturing point of view only the modules linked to casting costs and additive manufacturing cost were computed, because of the changing design features under analysis had a negligible impact on other dimensions (e.g. cleaning process, tooling operations or manufacturing logistic).

\subsection{Reflections from the case study application}

While the aerospace sector provides an interesting testbed for the implementation of the proposed approach, this activity does not come without challenges. The generic gas turbine jet engine architecture is generally stable since its introduction in the '50. This is beneficial for the researchers because it makes possible to exploit a large amount of historical data to ensure quality and reliability of geometrical, performance and cost models used in the calculation. On the other hand, the long development lead times of aircraft components hinder the possibility of verifying the industrial benefit of the proposed approach. A different set of measurable success criteria shall then be defined, the main one being the ability of the approach to raise awareness about PSS cost during concept design, and to nurture discussion on PSS cost issues within the cross-functional engineering team. This is in accordance to the idea of using models as boundary objects around which to focus the discussion for cross-functional collaboration (Carlile, 2002). Verification activities were performed in accordance to what prescribed by the Design Research Methodology (Blessing and Chakrabarti, 2009) in terms of Support Evaluation and Application Evaluation. The Support Evaluation activity took place to determine whether the proposed approach was sufficiently consistent in its functionality to proceed to a further implementation. This activity consisted of verifying if the function intended to be integrated into the model were, indeed, addressed. The authors gathered feedback from industrial practitioners by means of bi-weekly status updates between researchers and practitioners and company internal presentation. The Application Evaluation aimed, instead, at verifying the applicability and usability of the approach, ensuring consistency of the built-in functionalities. This was done by testing the approach in several iterations based on variations of the TRS case study and verifying the repeatability of the results. Overall, practitioners recognize that the main benefit of the model-based cost engineering approach is that of forcing the PSS design team to play with the notion of life cycle 'value' in a way that is not supported by traditional requirements management practices. Life cycle-related issues are not typically included in early hardware development activities, mainly because the engineering models used at the company are performance-based and do not naturally embed through life issues. Hence, the approach is acknowledged to be beneficial in the way it pushes the design team in understanding the rationale and the intent behind the requirements list, with life cycle cost being the boundary object nurturing conversations and tacit knowledge sharing across the team. 


\subsection{Reflections on the main areas for improvement}

Future work will aim at fostering the way the reliability of the cost engineering results is communicated to the decision makers. It will also explore the use of data mining techniques to improve the quality of the cost models, and its ability to deal with radically different hardware designs.

Today the approach does neither integrate methods for uncertainty measurement nor provides indications about the reliability of the output data. Even though the model is not meant to replace expert decision-making, the availability of a precise monetary indicator gives engineers a false sense of precision. It is vital for the consistency of the decisions that the model is not considered as a cost optimization tool rather as a support to raise engineers' awareness on expected life cycle costs. The further development of the approach would need to focus on the integration of a model reliability assessment system.

The Descriptive Study also revealed that gut feelings and personal experience still play a key role in engineering decision making. However, in many cases the engineering team is a newcomer in the PSS world, being unable to foresee how product and service features will mutually interact and how they will impact on cost. Failing to consider these synergies means for the engineering team to fall into the trap of considering PSS cost as the mere sum of product costs and service cost separately (as pointed out by Kambanou and Lindahl, 2016). The opportunity to exploit data mining techniques might help raising the level of awareness of PSS as a whole. A data-driven approach might support the design team in unveiling hidden correlations between technical features of the product and its life cycle cost performances in a PSS context, hence deriving more 'factual' predictive cost functions that reduce the uncertainty of the calculations. For an aero engine component, life cycle data collection activities would span over several years, due to the very long product life cycle. However, it can be assumed that in other PSS contexts these would require considerably less time, especially in business to consumer cases where data about the usage phase are constantly created (e.g. the bike sharing example described by Estrada et al., 2017)

Eventually, the presented approach is well suited for situations in which design options belong to a relatively static system, not being too radically different in terms of both geometrical and functional representations. This is typical of long and complex development processes, in which product requirements are frozen in early stages and are cascaded to both internal and external organization and suppliers, causing late design modifications and rework to be highly expensive. When it comes to assessing the cost of radically different design alternatives, the approach is still of limited use. This is because the cost models would require as input the results of early simulations from different CAE tools, and the use of different cost estimation modules, whose results would not be comparable in relative terms since missing a common baseline for the trade-off. In other words, in the presence of radically different concepts, the risk would be that of "comparing apples with oranges", thus providing irrelevant information for decision making. 


\section{Conclusion}

The model-based approach proposed in this paper is based on parametric techniques linked to relevant cost assessment modules, which are identified on a case-basis from a list of PSS Total Cost of Ownership dimensions. A main feature of the approach is the ability to explore the design space by running cost estimation based on many possible design variations rather than on a predefined set of solutions.

The ability to gather and share knowledge and values while exploring the design space using model generated data is believed to be a critical capability augment decision making in PSS concept design. Creating an environment where the cross-functional team can visually link cost to PSS concepts is a necessary step towards enabling more value-oriented decisions in PSS design. The main function of the proposed cost engineering approach is therefore to support the systematic evaluation of conceptual sub-system hardware in a way that goes beyond the requirement description. This raised awareness shall facilitate negotiation of PSS features across organizational functions and roles.

The model-based approach for PSS cost engineering described in this paper shall be considered a part of a larger research initiative targeting the creation of a multidisciplinary model-driven development approach for PSS design. This wider research effort targets the creation of a multi-model and multi-disciplinary decisionmaking environment for engineering design decision making, exploiting the use of collaborative visualization technologies linked to modelling and simulation. Additional research is currently testing the proposed approach in several different cases in the building and road construction industry to further confirm the validity and generalizability of the findings.

\section{Acknowledgmentss}

The research has received financial support from the Swedish Knowledge and Competence Development Foundation through the Model Driven Development and Decision Support research profile at Blekinge Institute of Technology, and from the Swedish Governmental Agency for Innovation Systems (VINNOVA), in the frame of the NFFP \& VITUM project.

\section{References}

Avison, D.E., Lau, F., Myers, M.D., Nielsen, P.A., 1999. Action research. Communication of ACM, 42(1), pp. 94-97.

Ahamed, Z., Inohara, T., \& Kamoshida, A. (2013). The servitization of manufacturing: An empirical case study of IBM corporation. International Journal of Business Administration, 4(2), 18. 
AIRBUS, 2016. Aircraft characteristics airport and maintenance planning, <online> available at:

http://www.aircraft.airbus.com/fileadmin/media_gallery/files/tech_data/AC/AC_ A380_20161201.pdf accessed on October 24th, 2017

Alonso-Rasgado, T., Thompson, G., \& Elfström, B. O. (2004). The design of functional (total care) products. Journal of engineering design, 15(6), 515-540.

Asiedu, Y., \& Gu, P. (1998). Product life cycle cost analysis: state of the art review. International journal of production research, 36(4), 883-908.

Aurich, J. C., Mannweiler, C., \& Schweitzer, E. (2010). How to design and offer services successfully. CIRP Journal of Manufacturing Science and Technology, 2(3), 136-143.

Baines, T. S., Lightfoot, H. W., Benedettini, O., \& Kay, J. M. (2009). The servitization of manufacturing: A review of literature and reflection on future challenges. Journal of manufacturing technology management, 20(5), 547-567.

Bertoni, A., Amnell, H., Isaksson, O., (2015) Value modelling in aerospace sub-system design: linking quantitative and qualitative assessment, Proceedings of the 20th International Conference on Engineering Design - ICED 2015, C. Weber, S. Husung, G. Cascini, M. Cantamessa, D. Marjanovic, M. Bordegoni (eds.), Design Society, Milan, 2015, pp 421-430.

Bertoni, M., Panarotto, M., \& Larsson, T. C. (2016). Boundary objects for PSS design. Procedia CIRP, 47, 329-334.

Blanchard, B. S., Fabrycky, W. J., \& Fabrycky, W. J. (1990). Systems engineering and analysis (Vol. 4). Englewood Cliffs, NJ: Prentice Hall.

Blessing, L. T., \& Chakrabarti, A. (2009). DRM: A Design Reseach Methodology (pp. 13-42). Springer London.

Boeing, 2015. 787 Airplane Characteristics for Airport Planning. <online>, available at http://www.boeing.com/assets/pdf/commercial/airports/acaps/787.pdf accessed on October 24th, 2017

Bonetti, S., Perona, M., \& Saccani, N. (2016). Total Cost of Ownership for ProductService system: application of a prototypal model to aluminum melting furnaces. Procedia CIRP, 47, 60-65.

Carlile, P.R. (2002). A Pragmatic View of Knowledge and Boundaries: Boundary Objects in New Product Development. Organization Science 2002, 13 (4), 442455. 
Chougule, R. G., \& Ravi, B. (2006). Casting cost estimation in an integrated product and process design environment. International Journal of Computer Integrated Manufacturing, 19(7), 676-688.

Cooper, R. G. (2008). The stage-gate idea-to-launch process-update, what's new and NexGen systems. Journal of Product Innovation Management, 25(3), 213-232.

Datta, P. P., \& Roy, R. (2010). Cost modelling techniques for availability type service support contracts: a literature review and empirical study. CIRP Journal of Manufacturing Science and Technology, 3(2), 142-157.

Dorn, J., Seiringer, W. (2012) A cost model for Services. In Collaborative Networks in the Internet of Services. Camarinha-Matos, L. M., Xu, L., \& Afsarmanesh, (Eds.) vol. 380. Berlin, Heidelberg: Springer Berlin Heidelberg; 2012. doi:10.1007/978-3-642-32775-9.

Durugbo, C. (2014). Strategic framework for industrial product-service co-design: findings from the microsystems industry. International Journal of Production Research, 52(10), 2881-2900.

Ellram, L. (1993). Total cost of ownership: elements and implementation. Journal of Supply Chain Management, 29(3), 2-11.

Erkoyuncu, J. A., Durugbo, C., Shehab, E., Roy, R., Parker, R., Gath, A., \& Howell, D. (2013). Uncertainty driven service cost estimation for decision support at the bidding stage. International Journal of Production Research, 51(19), 5771-5788.

Estrada, A., \& Romero, D. (2016). Towards a Cost Engineering Method for ProductService Systems based on a System Cost Uncertainty Analysis. Procedia CIRP, 47, 84-89.

Estrada, A., Romero, D., Pinto, R., Pezzotta, G., Lagorio, A., \& Rondini, A. (2017). A Cost-Engineering Method for Product-Service Systems Based on Stochastic Process Modelling: Bergamo's Bike-Sharing PSS. Procedia CIRP, 64, 417-422. FAA, Federal Aviation Administration, 2009. Advisory Circular: Guidance Material for Aircraft Engine life-limited parts requirements. Available online at: https://www.faa.gov/documentLibrary/media/Advisory_Circular/AC33.70-1.pdf accessed on November 20th, 2017.

Feldman, P., \& Shtub, A. (2006). Model for cost estimation in a finite-capacity environment. International journal of production research, 44(2), 305-327. 
Finken, K. H., McAloone, T. C., Avlonitis, V., Garcia i Mateu, A., Andersen, J. A. B., Mougaard, K., Neugebauer, L.M \& Hsuan, J. (2013). PSS Tool Book: A workbook in the PROTEUS series. Technical University of Denmark (DTU).

Gershenson, J., and Ishii, K., (1993)., Life-cycle design for serviceability. In Concurrent Engineering: Automation, Tools, and Techniques, A. Kusiak (ed.) (New York: Wiley), $363 \pm 384$.

Giunta, A.A., Wojtkiewicz, S.F. \& Eldred, M.S. (2003). Oveview of modern design of experiment methods for computational simulation. 41st Aerospace Sciences Meeting and Exhibit, Reno, Nevada.

Goedkoop, M. J., Van Halen, C. J., Te Riele, H. R., \& Rommens, P. J. (1999). Product service systems, ecological and economic basics. Report for Dutch Ministries of environment (VROM) and economic affairs (EZ), 36(1), 1-122.

Goncalves, C. D., \& Kokkolaras, M. (2015, August). Value-Driven Modeling of Tactical and Operational Decisions in Support of Aerospace Product-Service Systems Design. In ASME 2015 International Design Engineering Technical Conferences and Computers and Information in Engineering Conference (pp. V02BT03A044-V02BT03A044). American Society of Mechanical Engineers.

Gupta, Y. P. (1983). Life cycle cost models and associated uncertainties. In Electronic Systems Effectiveness and Life Cycle Costing (pp. 535-549). Springer Berlin Heidelberg.

ICAO, NN. ICAO Carbon Emissions Calculation Methodology, Version 10. (June 2017). - online- Accessed on October 19th, 2017 available at https://www.icao.int/environmentalprotection/CarbonOffset/Documents/Methodology\%20ICAO\%20Carbon\%20Ca lculator_v10-2017.pdf

Isaksson, O., Bertoni, M., Hallstedt, S., \& Lavesson, N. (2015). Model Based Decision Support for Value and Sustainability in Product Development. In 20th International Conference on Engineering Design (ICED), Milan. The Design Society.

Isaksson, O., Kossmann, M., Bertoni, M., Eres, H., Monceaux, A., Bertoni, A., Wiseall, S., Zhang, X. (2013). Value-driven design: a methodology to link expectations to technical requirements in the extended enterprise. In: Proceedings of the 23rd Annual INCOSE International Symposium 2013. 
Isaksson, O., Larsson, T. C., \& Rönnbäck, A. Ö. (2009). Development of productservice systems: challenges and opportunities for the manufacturing firm. Journal of Engineering Design, 20(4), 329-348.

Kambanou, M. L., \& Lindahl, M. (2016). A Literature Review of Life Cycle Costing in the Product-Service System Context. Procedia CIRP, 47, 186-191

Kennedy, M., Harmon, K., Minnock, E., (2008) Ready, Set, Dominate: Implement Toyota's Set-Based Learning for Developing Products and Nobody Can Catch You, The Oaklea Press.

Kimita, K., Tateyama, T., \& Shimomura, Y. (2012). Process simulation method for product-service systems design. Procedia CIRP, 3, 489-494.

Kitzinger, J. (1995). Qualitative research. Introducing focus groups. BMJ: British medical journal, 311(7000), 299.

Krenek, A., \& Schratzenstaller, M. (2016). Sustainability-oriented EU Taxes: The Example of a European Carbon-based Flight Ticket Tax. FairTax working paper series, No. 1, 39p.

Kreye, M., Goh, Y. M., \& Newnes, L. B. (2009). Uncertainty in through life costing within the concept of product service systems: a game theoretic approach. In DS 58-7: Proceedings of ICED 09, the 17th International Conference on Engineering Design, Vol. 7, Design for X/Design to X, Palo Alto, CA, USA, 24.-27.08. 2009.

Kreye, M.E., Newnes, L.B. \& Mey Goh, Y. (2013). Information availability at the competitive bidding stage for service contracts. Journal of Manufacturing Technology Management, 24(7), 976-997.

Kumar, R., \& Markeset, T. (2007). Development of performance-based service strategies for the oil and gas industry: a case study. Journal of Business \& Industrial Marketing, 22(4), 272-280.

Johansson, C., Hicks, B., Larsson, A. C., \& Bertoni, M. (2011). Knowledge maturity as a means to support decision making during product-service systems development projects in the aerospace sector. Project Management Journal, 42(2), 32-50.

Levandowski, C., Michaelis, M. T., \& Johannesson, H. (2014). Set-based development using an integrated product and manufacturing system platform. Concurrent Engineering, 22(3), 234-252. 
Lightfoot, H., Baines, T., \& Smart, P. (2013). The servitization of manufacturing: A systematic literature review of interdependent trends. International Journal of Operations \& Production Management, 33(11/12), 1408-1434.

Lindahl, M., Sundin, E., \& Sakao, T. (2014). Environmental and economic benefits of Integrated Product Service Offerings quantified with real business cases. Journal of cleaner production, 64, 288-296.

Löfstrand, M., Andrews, J., Karlberg, M., \& Karlsson, L. (2011). Functional product system availability: simulation-driven design and operation through coupled multi-objective optimisation. International Journal of Product Development, 13(2), 119-131.

Marchi, B., Zanoni, S., Mazzoldi, L., \& Reboldi, R. (2016). Product-service System for Sustainable EAF Transformers: Real Operation Conditions and Maintenance Impacts on the Life-cycle Cost. Procedia CIRP, 47, 72-77.

McNiff, J. (2014). Writing and doing action research. Sage.

Meier, H., Roy, R., \& Seliger, G. (2010). Industrial product-service systems-IPS 2. CIRP Annals-Manufacturing Technology, 59(2), 607-627.

Monceaux, A., Kossmann, M., Wiseall, S., Bertoni, M., Isaksson, O., Eres, H., Bertoni, A. \& Rianantsoa, N. (2014). Overview of Value-Driven Design Research: Methods, Applications, and Relevance for Conceptual Design. Insight, 17(4), 37-39.

Morelli, N. (2006). Developing new product service systems (PSS): methodologies and operational tools. Journal of Cleaner Production, 14(17), 1495-1501.

Navin-Chandra, D. (1993, August). ReStar: A design tool for environmental recovery analysis. In 9th International Conference on Engineering Design (pp. 780-787). The Hague, Heurista, Zurich, Switzerland. 780-787.

Newnes, L., Mileham, A. R., Cheung, W. M., \& Goh, Y. M. (2011). Through Life Costing. In Service Design and Delivery (pp. 135-151). Springer US.

Romero Rojo, F. J., Roy, R., Shehab, E., Cheruvu, K., \& Mason, P. (2012). A cost estimating framework for electronic, electrical and electromechanical (EEE) components obsolescence within the use-oriented product-service systems contracts. Proceedings of the Institution of Mechanical Engineers, Part B: Journal of Engineering Manufacture, 226(1), 154-166. 
Sakao, T., \& Lindahl, M. (2015). A method to improve integrated product service offerings based on life cycle costing. CIRP Annals-Manufacturing Technology, 64(1), 33-36.

Sandberg, M., Boart, P., \& Larsson, T. (2005). Functional product life-cycle simulation model for cost estimation in conceptual design of jet engine components. Concurrent Engineering, 13(4), 331-342.

Schuh, G., Riesener, M., Breunig, S., Koch, J., \& Kuntz, J. (2017). Evaluation of Variety-induced Costs in Product-Service Systems (PSS). Procedia CIRP, 61, 673-678.

Seemann, R., Langhans, S., Schilling, T., \& Gollnick, V. (2010). Modeling the life cycle cost of jet engine maintenance. Technische Universität Hamburg-Harburg (TUHH), Hamburg.

Seiringer, W., \& Bauer, W. (2016). Improving PSS Costing Based on Customer Integration. Procedia CIRP, 47, 36-41.

Settanni, E., Newnes, L. B., Thenent, N. E., Parry, G., \& Goh, Y. M. (2014). A throughlife costing methodology for use in product-service-systems. International Journal of Production Economics, 153, 161-177.

Shen, J., Erkoyuncu, J. A., Roy, R., \& Wu, B. (2017). A framework for cost evaluation in product service system configuration. International Journal of Production Research, 1-25.

Sobek, D. K., Ward, A. C., \& Liker, J. K. (1999). Toyota's principles of set-based concurrent engineering. Sloan management review, 40(2), 67.

Speziale, H. S., Streubert, H. J., \& Carpenter, D. R. (2011). Qualitative research in nursing: Advancing the humanistic imperative. Lippincott Williams \& Wilkins.

Sun, H., Liu, Y., Sakao, T., \& Wang, Z. (2017). Configuring use-oriented aero-engine overhaul service with multi-objective optimization for environmental sustainability. Journal of Cleaner Production, 162, S94-S106.

Thomsen, B., Kokkolaras, M., Månsson, T., \& Isaksson, O. (2017). Quantitative Assessment of the Impact of Alternative Manufacturing Methods on Aeroengine Component Lifing Decisions. Journal of Mechanical Design, 139(2), 021401.

Vallhagen, J., Isaksson, O., Söderberg, R., \& Wärmefjord, K. (2013). A framework for producibility and design for manufacturing requirements in a system engineering context. Procedia CIRP, 11, 145-150. 
Visintin, F. (2014). Photocopier industry: At the forefront of servitization. In Servitization in industry (pp. 23-43). Springer, Cham.

Wallin, J. (2013). The Servitization of the Aerospace Industry and the effects on product development. In Proceedings of the 4th CEAS Air and Space Conference, Linköping, Sweden, September 16th-19th.

Wallin, J., Parida, V., \& Isaksson, O. (2015). Understanding product-service system innovation capabilities development for manufacturing companies. Journal of Manufacturing Technology Management, 26(5), 763-787.

Ward, Y., \& Graves, A. (2007). Through-life management: the provision of total customer solutions in the aerospace industry. International Journal of Services Technology and Management, 8(6), 455-477.

Whyte, W. F., Greenwood, D. J., Lazes, P. (1989). Participatory action research: Through practice to science in social research. American Behavioral Scientist, 32(5), 513-551

Wilberg, J., Maisenbacher, S., \& Lindemann, U. (2016). Proactive Cost Management: Integrating Use Phase Data to Reduce Uncertainty. In NordDesign 2016.

Wohlin, C. (2014). Guidelines for snowballing in systematic literature studies and a replication in software engineering. In Proceedings of the 18th International Conference on Evaluation and Assessment in Software Engineering. ACM p. 38.

Woodward, D. G. (1997). Life cycle costing - theory, information acquisition and application. International journal of project management, 15(6), 335-344.

Xu, Y., Elgh, F., Erkoyuncu, J. A., Bankole, O., Goh, Y., Cheung, W. M., ... \& Newnes, L. (2012). Cost engineering for manufacturing: current and future research. International Journal of Computer Integrated Manufacturing, 25(4-5), 300-314.

Yutko, B. M. (2011). Approaches to representing aircraft fuel efficiency performance for the purpose of a commercial aircraft certification standard (Doctoral dissertation, Massachusetts Institute of Technology).

Zhang, H., Haapala, K. R., Mary, E., \& Funk II, K. H. (2011). Environmental impact and cost assessment of product service systems using IDEF0 modeling. Proceedings of NAMRI/SME, 39. 